ارزيابى تنوع و كاربرد صفات زراعى، مورفولوزيك و فيزيولوزيك جهت بهبود عملكرد دانه كينوا

سيد سعيد موسوى "*، رضا مرادى ريزوندى '، محمدرضا عبداللهى بّ و محمود باقرى

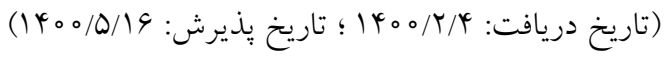

حكکب:

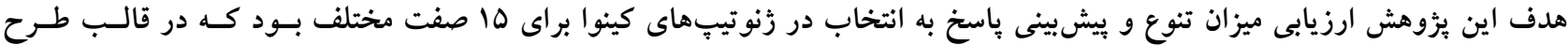

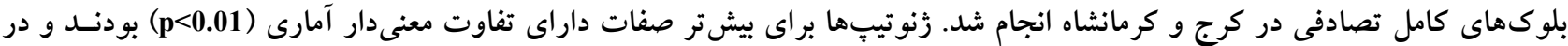

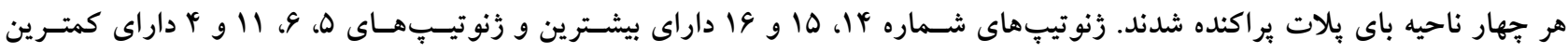

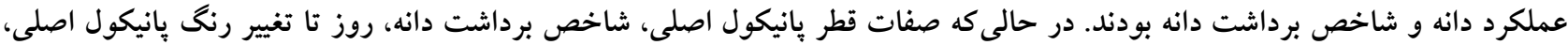

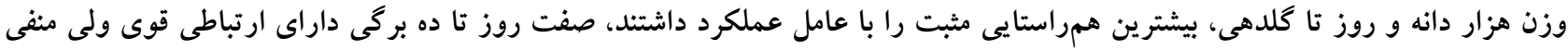

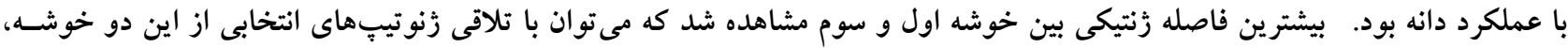

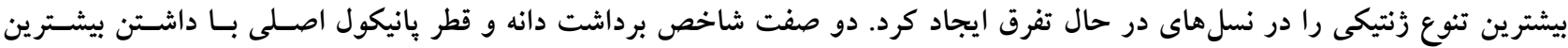

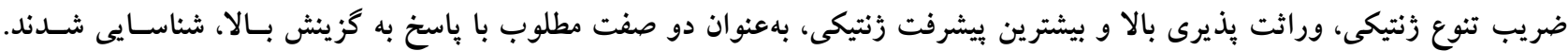

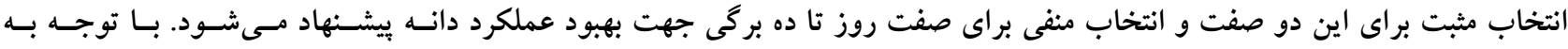

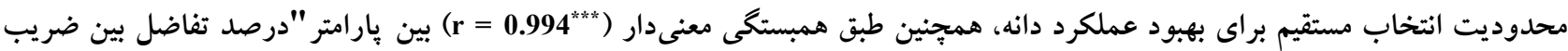

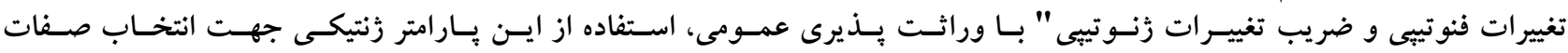

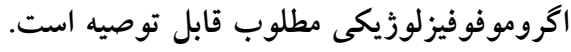

وازههاى كليدى: صفات كيفى، صفات مورفوفيزيولوزيكى، ياسخ به انتخاب، تجزيه به عاملها، تجزيه خوشهاى

ا، r و لا. بهترتيب دانشيار، دانشجوى كارشناسى ارشد و دانشيار، گروه زراعت و اصلاح نباتات (مهندسى توليــ و زنتيـك گيـاهى)، دانشـكده كشـاورزى، دانشخاه بوعلى سينا، همدان، ايران ץ. استاديار موسسه تحقيقات اصلاح و تهيه نهال و بذر. سازمان تحقيقات، آموزش و ترويج كشاورزى، كرج، ايران

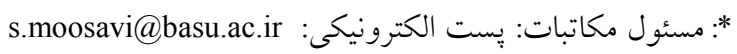


مطلوب نوظهور را مسى طلبــ (Yr). در ايـن بـاره، ارزش غــذايى

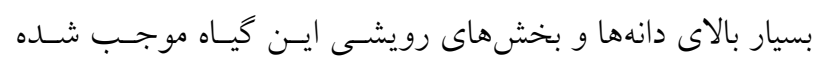

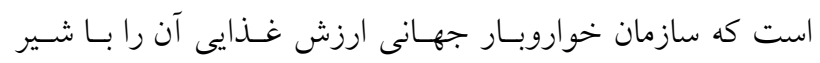

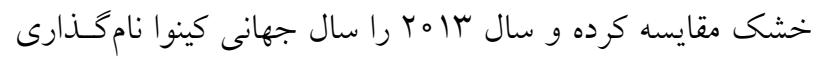

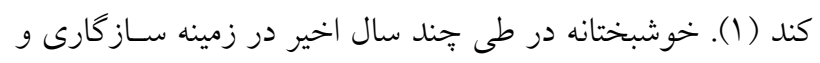

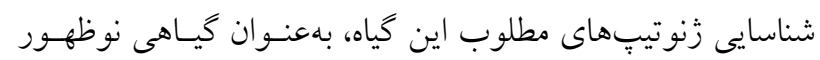

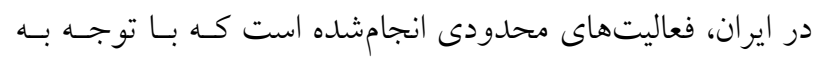

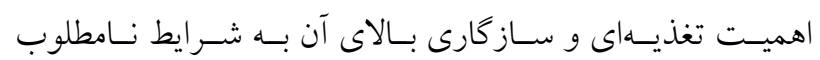

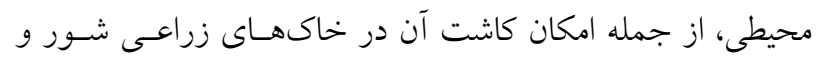

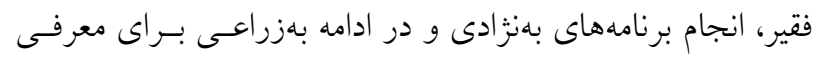

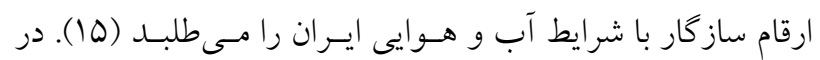

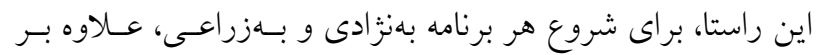

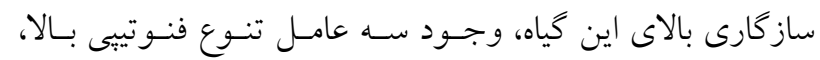

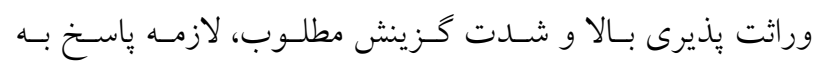

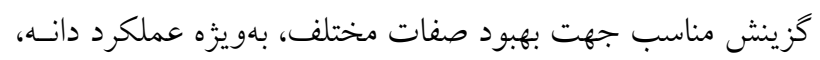

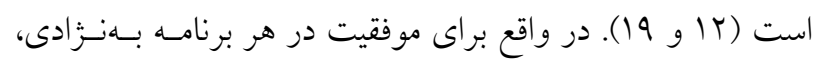

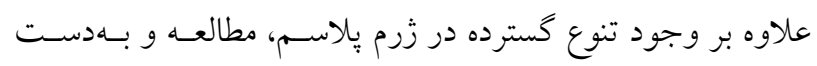

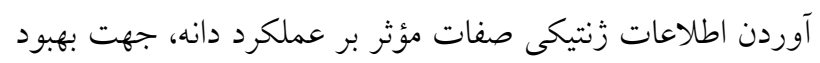

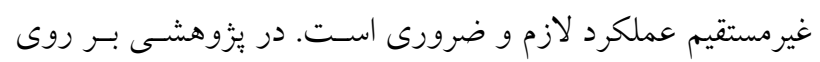

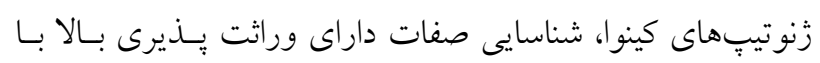

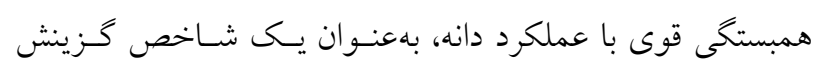

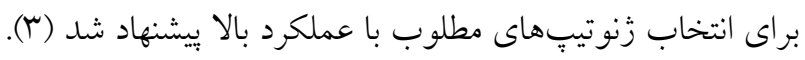

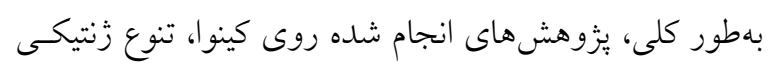

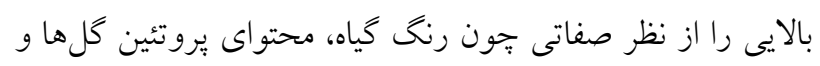

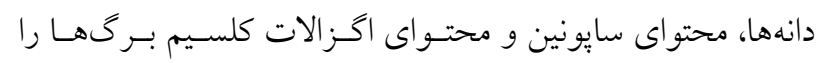

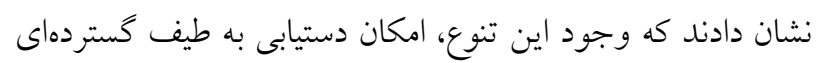
از سازكارى با شرايط مختلـف محيطى را فـراهم مسى كنــ (TO (T).

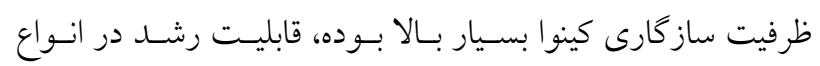

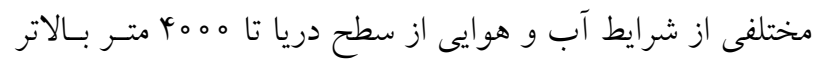

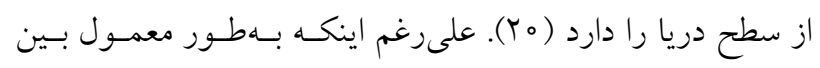

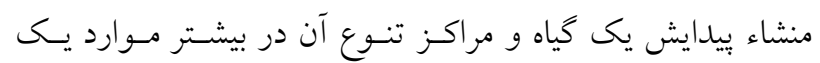

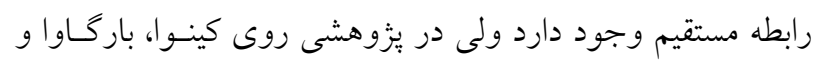

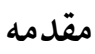

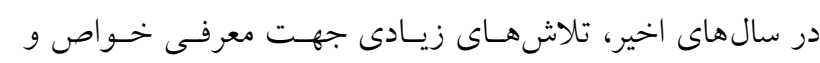

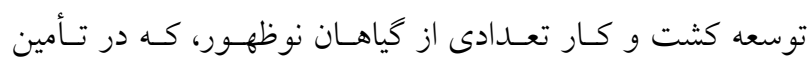
نيازهاى تغذيهاى انسان نقش مهمى دارند، انجام شده است (IV) در اين راستا، توسعه كشت و كار گياهان شبه غلات، بهويزه خيـاه

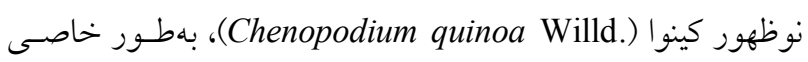

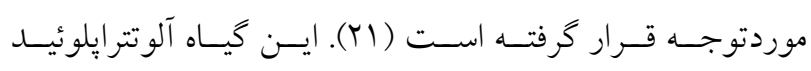
حن (Yn=YX=r4)

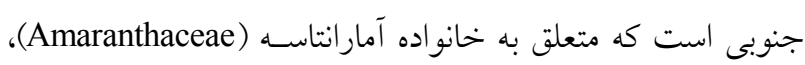

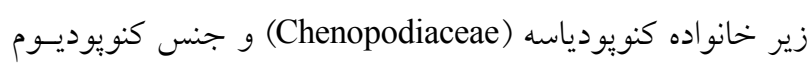
است (Thenopodium)

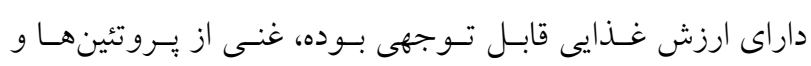

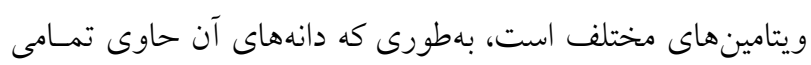

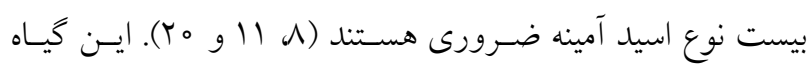

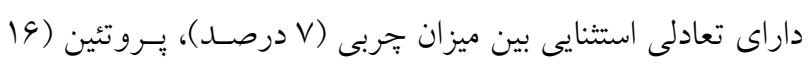

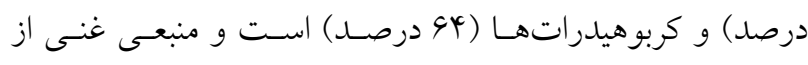

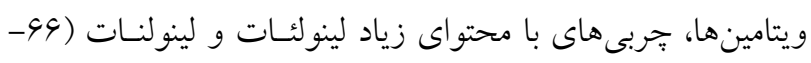

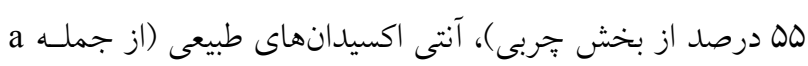

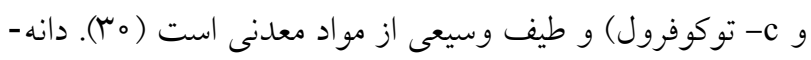

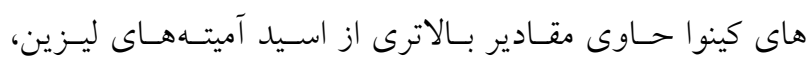

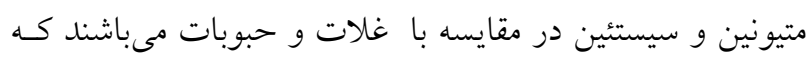

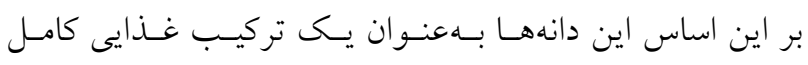

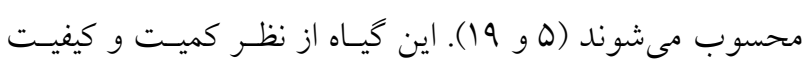

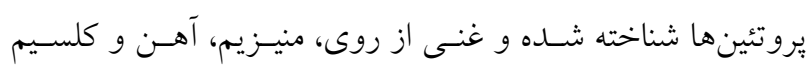

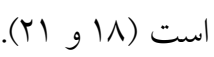

با توجه به كـاهش تنـوع زيستى محصـولات زراعس، خطـر كمبود مواد مغذى و مشكل امنيت غــذايى روز بـهـ روز آشـكارتر

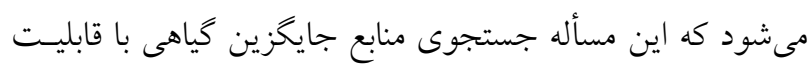

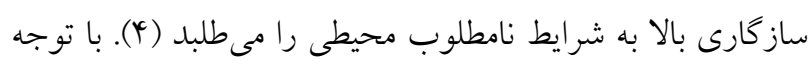

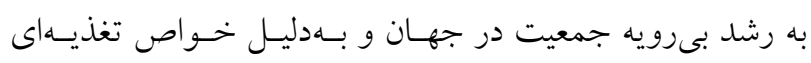

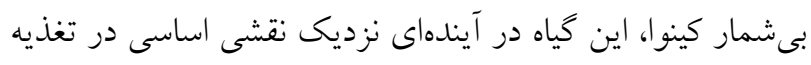

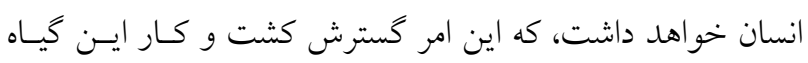


خواهند شد (V). دىسانتيس و همكاران (0 (1) اظهار داشـتند كـه تخمين وراثت بذيرى در بيشتر صفات اكروموفولوزيكى در كينسوا

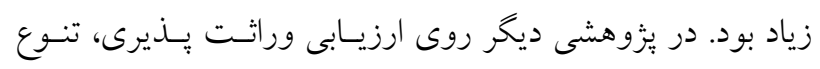

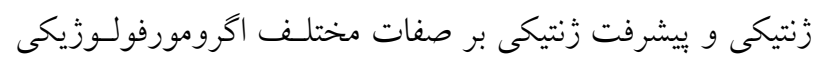

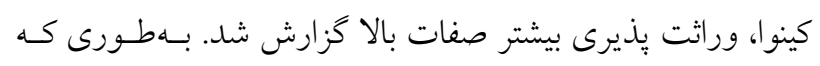

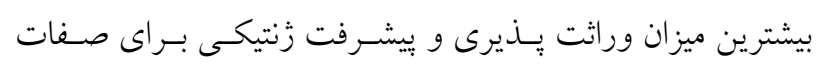

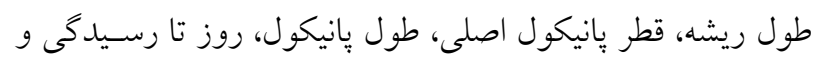

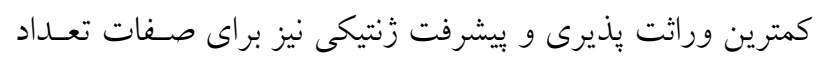

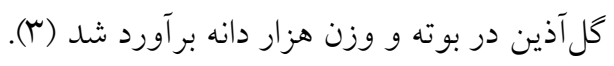

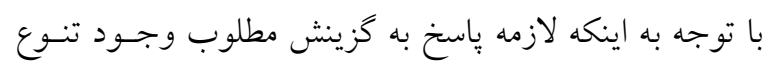

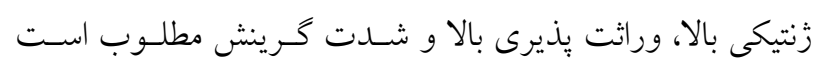

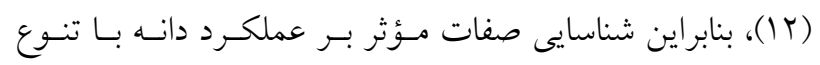

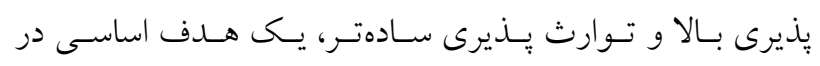

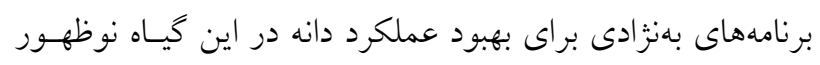

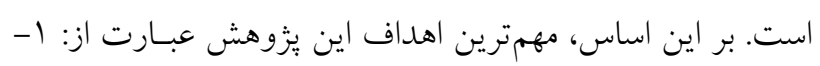

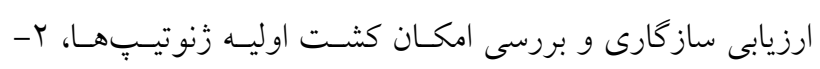

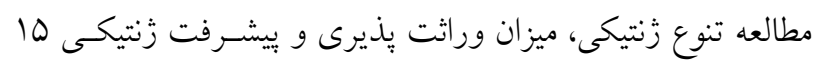

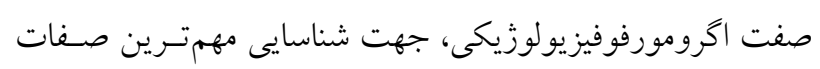

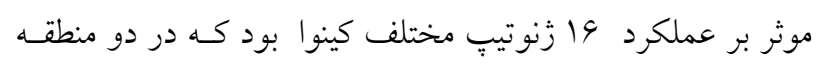
كرج و كرمانشاه انجام شد.

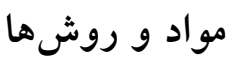

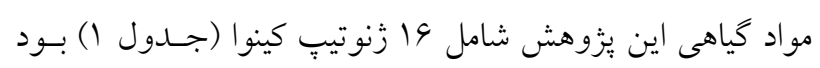

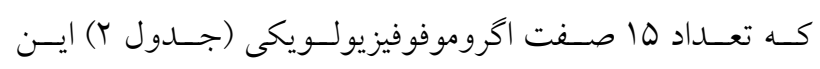

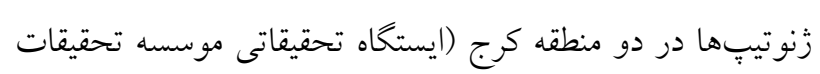

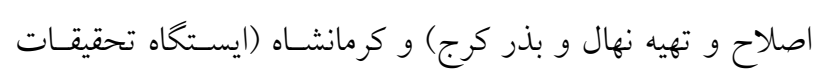

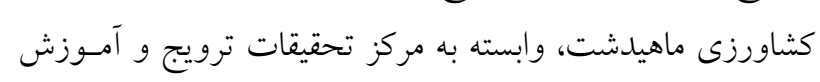

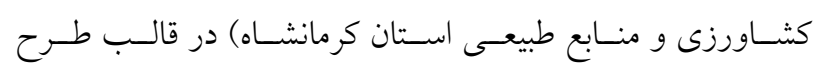

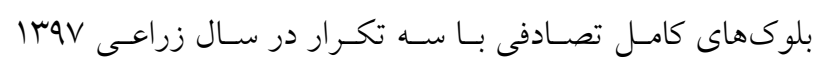

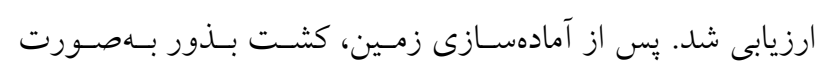

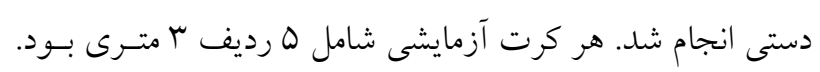

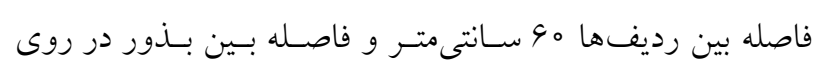

همكاران (9) اظهار داشتند كه رابطهاى مستقيم بـين تنسوع در زرم

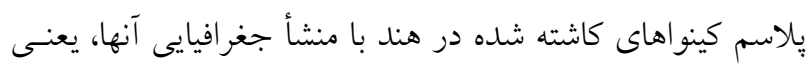

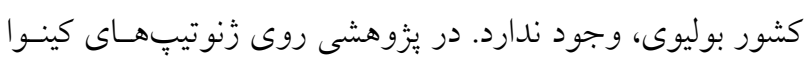

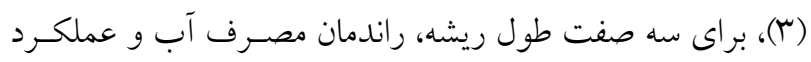

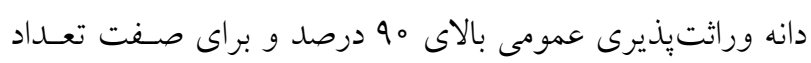

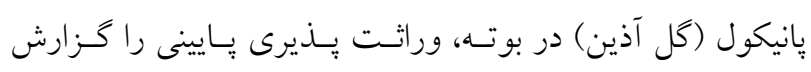

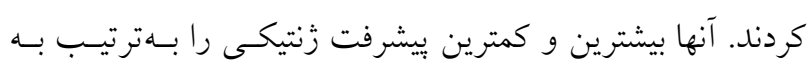

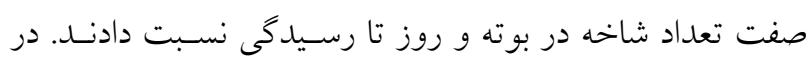

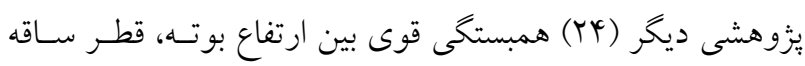

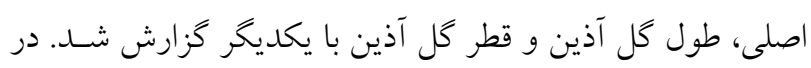

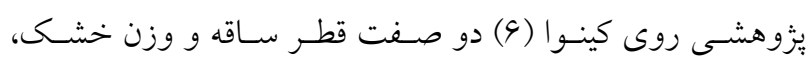

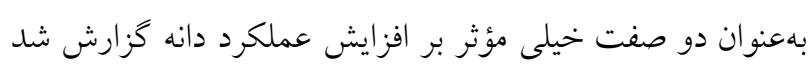

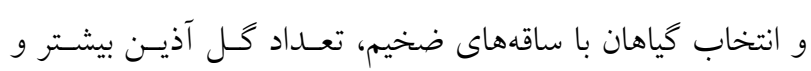

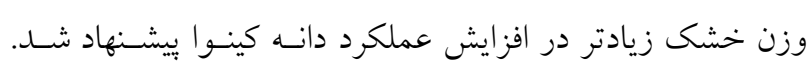

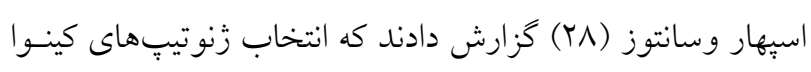
بر اساس طول يانيكول و قطر يانيكول اصلى ممكن است منجر به دادنه

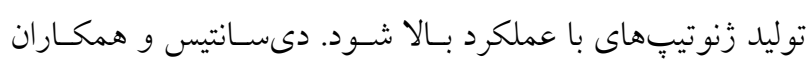

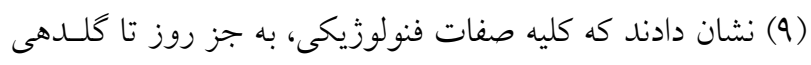

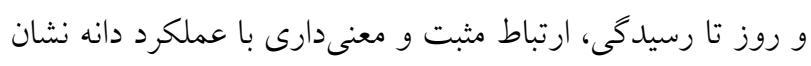

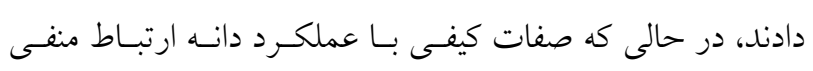

داشتند.

بلهور كلى تخمين بارامترهاى زننيكى، بلهويزه بــرآورد ميـزان

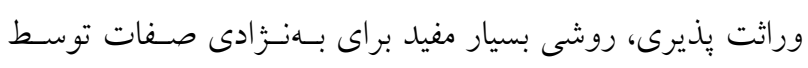

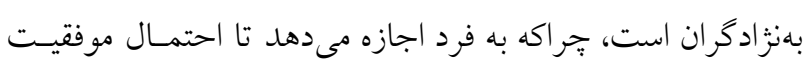

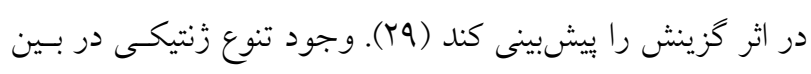

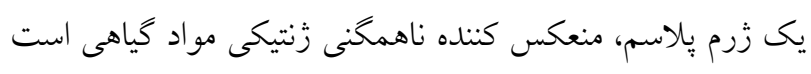

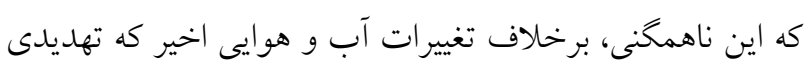

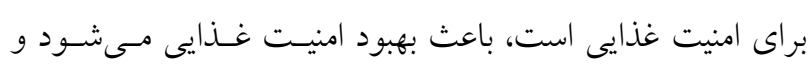

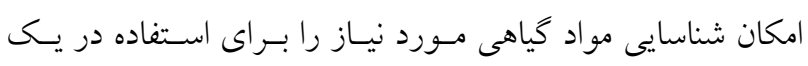

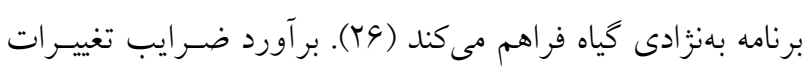

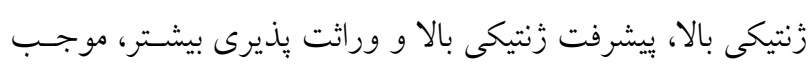

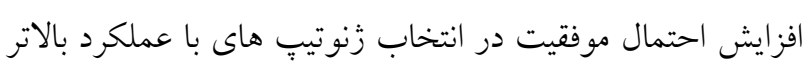


جدول ا. اطلاعات عا زنوتيب كينواى مطالعه شده در اين يُّوهش

\begin{tabular}{|c|c|c|c|}
\hline شماره و نام رزنوتيّ & محل تهيه & شماره و نام زنوتيبٍ & محل تهيه \\
\hline 1: EQ1 & كانادا & 9: EQ21 & فائو \\
\hline 2: EQ2 & كانادا & 10: EQ22 & فائو \\
\hline 3: EQ3 & كانادا & 11: EQ26 & فائو \\
\hline 4: EQ4 & 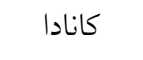 & 12: EQ29 & فائو \\
\hline 5: EQ5 & 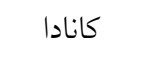 & 13: EQ31 & فائو \\
\hline 6: EQ6 & 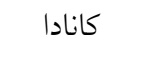 & 14: Titicaca & دانمارك \\
\hline 7: EQ12 & فائو & 15: Gizal & مصر \\
\hline 8: EQ18 & فائو & 16: Red carina & هلند \\
\hline
\end{tabular}

\begin{tabular}{|c|c|c|c|}
\hline اختصار & نام صفت & اختصار & نام صفت \\
\hline GYUA & عملكرد دانه در واحد سطح & DTL & روز تا ده بركى \\
\hline BYUA & عملكرد بيولوزيكى در واحد سطح & DF & روز تا كلدهى \\
\hline GHI & شاخص برداشت دانه & DPCC & روز تا تغيير رنخ يانيكول \\
\hline LWC & 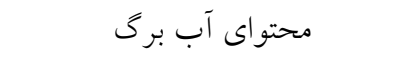 & DMG & روز تا شيرى شدن دانه \\
\hline TGW & وزن هزار دانه & DPM & روز تا رسيدگى فيزيولوزيكى \\
\hline GPP & درصد بِروتئين دانه & MSD & قطر ساقه اصلى \\
\hline GSP & درصد سايونين دانه & MPD & قطر پِانيكول اصلى \\
\hline ------- & -------- & GFP & طول دوره بِر شدن دانه \\
\hline
\end{tabular}

بركى از هر تكرار هر زنوتيتٍ بـهـور تصـادفى انتخـاب شـدند.

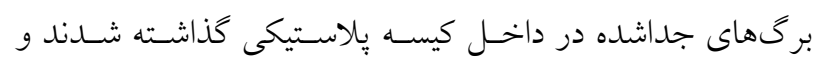

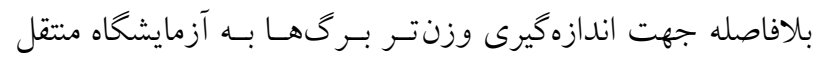

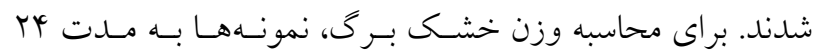

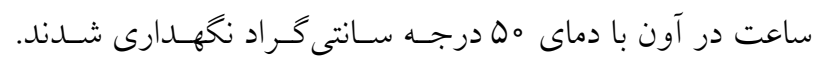
همجنين جهت اندازه گيرى درصد بروتئين دانه از روش كجلـدال و براى اندازه گيرى درصد سـايونين دانسه از روش كوزيسول (19) استفاده شد. براى ارزيابى تنوع و كاربرد صفات مختلف در بهبـود

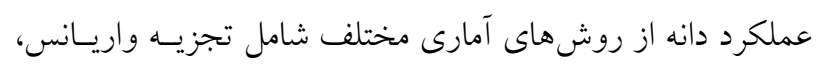
مقايسه ميانخينها، تجزيه به عاملها، تجزيـه خوشـهاى و تجزيسه

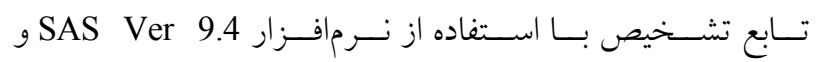

رديفها ه ا سانتى متر لحاظ شد. با توجه بـه سـطح زيـر كشـت، جهت تغذيه بوتههـا از كودهـاى شـيميايى بتـاس (س كيلـو رُم)،

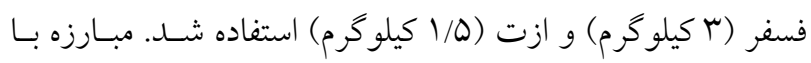
علفهاى هرز بهصورت دستى انجام شد. همجينين براى مبارزه با آفات از سم كنفيدر استفاده شد. دور آبيارى هر ه (در مراحل اول هرل

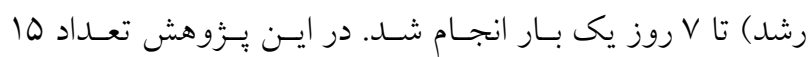

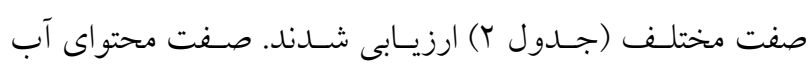
برى (LWC) از رابطه ا و به شرح ذيل محاسبه شدند: $\mathrm{LWC}=[(\mathrm{FW}-\mathrm{DW}) / \mathrm{DW}] \times 1$ 。

در روابط بالا FW و DW بهترتيـب بيـانگحر وزن تـر بـرى و وزن خشى برى بودند. براى اندازه گيرى صفات فوق، تعداد ها نمونه 
ضريب تغييرات فنوتيى و ضـريب تغييـرات زنسوتيبى، ضـريب

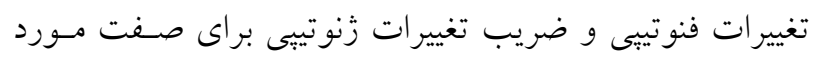
نظر است. - است

\section{نتايج و بحث}

\section{نتايج تجزيه واريانس و مقايسه ميانخينها}

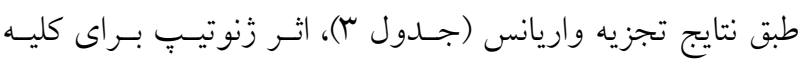
صفات، بهجز صفت درصد يروتئين دانه، داراى اختلاف معنسى دار

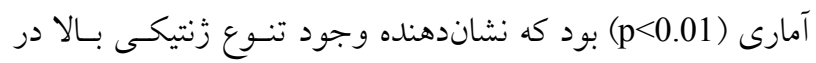
زرم پِلاسم مورد نظر براى صفات مطالعه شده است، بهطورى كـه

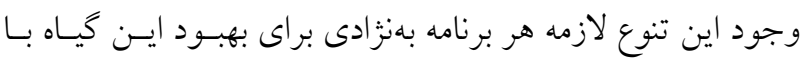

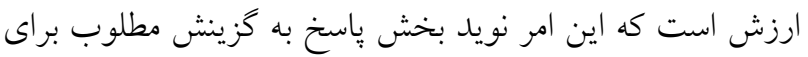

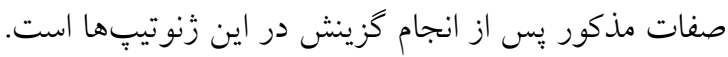
اثر مكان نيز براى كليه صفات بهجزء سه صفت قطر ساقه اصسلى،

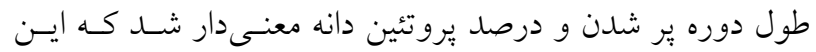
بيانكر نقش قابل توجه محيط، علاوه بر سهم زنوتيـٍ، در كتــرل اين صفات است. اثر متقابل زنوتيبّ در مكان نيز براى بيشـتر صـفات، بـهجـزء

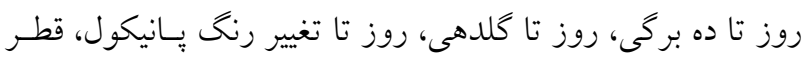

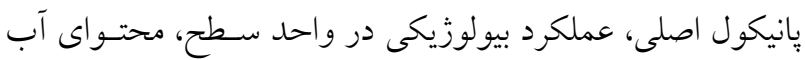
برى و توانايى حفظ آب در برى قطع شده معنى دار شد كـهـ ايـن

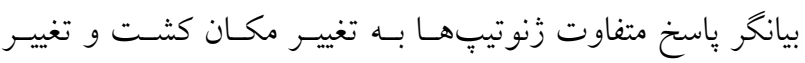

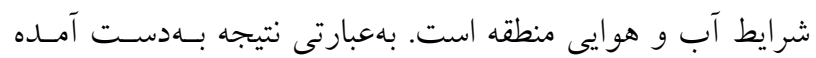

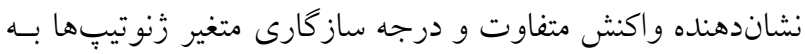

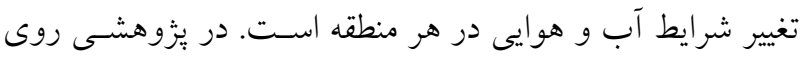

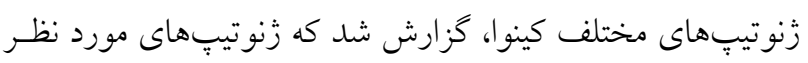

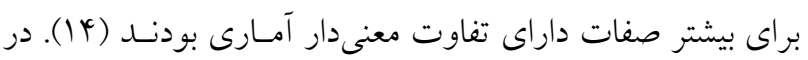

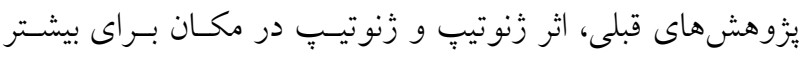

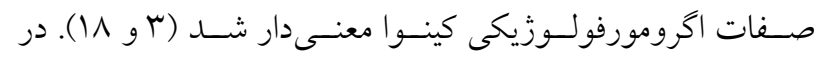

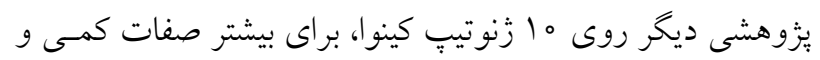

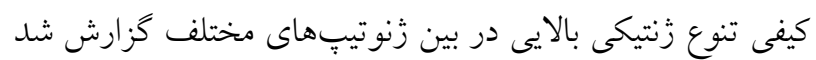

Minitab Ver. 16 و تجزيه تابع تشخيص با اسـتفاده از ميـانكين دادههـاى دو مكــان

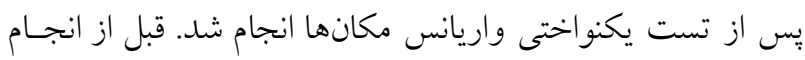

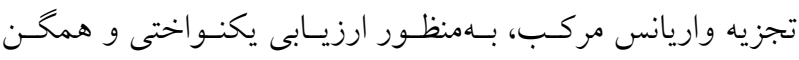

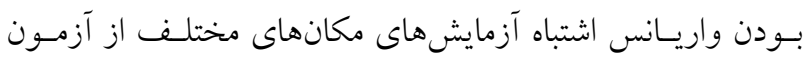

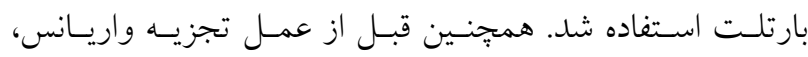
صادق بودن فرضـيات قبـل از عمـل تجزيـه واريـانس، از جملـه.

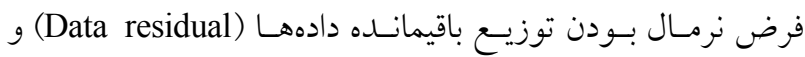

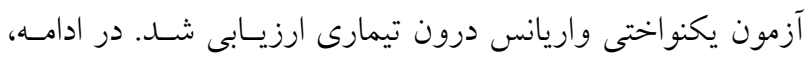
يارامترهاى زنتيكى مانند وراثتيذيرى عمومى و يِيشرفت زنتيكى

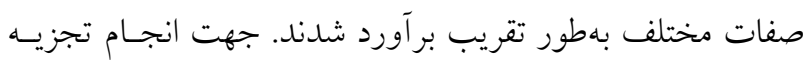

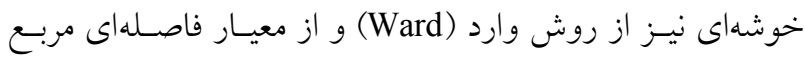
ييرسون، بهعنوان ماتريس فاصله، استفاده شد.

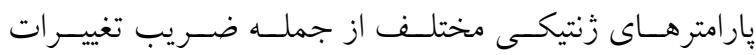

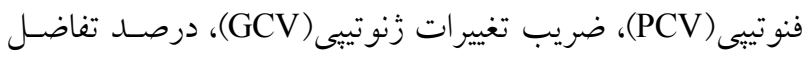

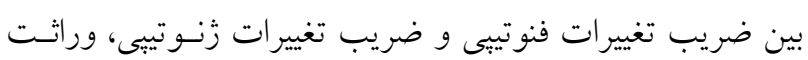
بذيرى عمومى، بيشرفت زنتيكى نسبت به ميانكين محاسبه شدند.

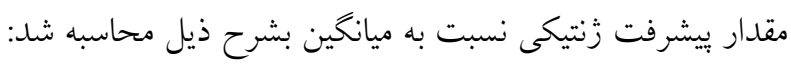

= بيشرفت زنتيكى $=G A=k \times \sqrt[r]{\sigma_{p h}^{r}} \times h^{r}$

= ويشرفت زنتيكى نسبت به ميانخين $=A A / \bar{X}$

در رابطه بالا k همان ديفرانسيل كزينش استاندارد شده اسـت كـه.

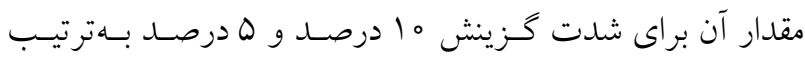

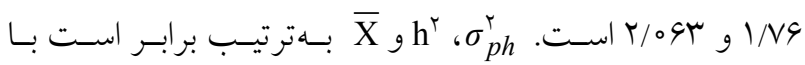
واريانس فنوتييى، وراثتيذيرى و ميانخين صفت مورد نظر است.

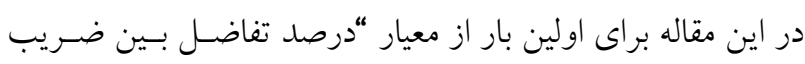

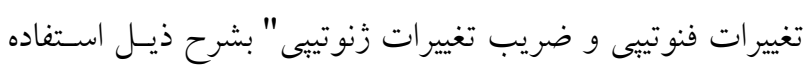
شد و اين معيار معرفى شد: Percentage of difference between phenotypic coefficient of variance and genotypic coefficient of variance $(\%)=$

PDPG $(\%)=\left[\frac{(P C V-G C V)}{(F C V)}\right] \times 100$ كه در آن PCP و PCV PCV بهت GCV بهتيب درصد تفاضل بسين 
جدول r. نتايج تجزيه واريانس مركب براى صفات مختلف در زنوتيبِهاى مختلف كينوا

\begin{tabular}{|c|c|c|c|c|c|c|c|c|}
\hline قطر پِانيكول & قطر ساقه & فيز يولوزيك رسيدى & شدز تا شيرى دانه & روز روز تانيكول تغير & روز تا گلدهى & روز تا دهى & آزادى درجه & منبع تغيير \\
\hline$\mu \varphi / \Delta Q^{* * *}$ & $\% 0 \Delta$ & $r V q / 0 q^{* * *}$ & $1 / 0^{* * *}$ & $\Delta \psi / 0^{* * *}$ & $\varphi / / V^{*}$ & $\varphi / 01^{*}$ & 1 & مكان \\
\hline $9 / 1 Y$ & $r / T V$ &.$/ 00$ & $\circ / 0 \wedge$ & $\circ / T V$ & $1 / 19$ & $1 / 4 \mu$ & $r$ & اشتباه اول \\
\hline$r q /\left.4\right|^{* *}$ & $\mid r / \wedge q^{* *}$ & $r|Y /| K^{* * *}$ & $r \& / 9 \Lambda^{* *}$ & $1 \vee 9 / \Lambda^{* * *}$ & $\left.r_{0 / 9}\right|^{* *}$ & $19 / 9 r^{\mu * *}$ & 10 & زنوتيب \\
\hline $0 / 001$ & $V / T^{* * *}$ & 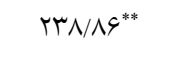 & $r / 9 \psi^{* * *}$ & $0 / 001$ & $\circ / \mu$ & $0 / 4 T$ & 10 & زنوتيّ × مكان \\
\hline$r / \circ \mathrm{V}$ & $1 / V 9$ & T/QT &.$/ 4$ & $\circ / \mu$ & $\circ / \mathrm{V}$ & $0 / 4 V$ & 90 & اشتباه دوم \\
\hline $1 \% / \Delta F$ & $10 / 10$ & $1 / 4$ & $0 / 49$ & $0 / 9 \mathrm{~V}$ & $1 / 11$ & $1 / 91$ & - & ضريب تغييرات \\
\hline
\end{tabular}

ادامه جدول r.

\begin{tabular}{|c|c|c|c|c|c|c|c|c|c|}
\hline سايونين & يروتئين دانه & وزن هزار & آب محتواى برى & شرداخص & بيولوزيك دملكرد & در وملكرد دانه & ير شدن دانه & آزادى درجه & منبع تغيير \\
\hline$\Delta V / 9 Q^{* *}$ & $10 / 90$ & $r q / 0 V^{* *}$ & $r / \Psi V^{* *}$ & $\wedge 11 \wedge^{* * *}$ & $r \circ \Delta \mid r \wedge \Delta^{* *}$ & $\Delta q V \backslash \backslash / K c^{* * * *}$ & $\circ / V G$ & 1 & مكان \\
\hline $0 / 09$ & 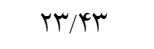 & $0 / 01$ & $0 / 01$ & rT人。 & QYMMOI & $r Y / M$ &.$/ 90$ & r & اشتباه اول \\
\hline$r / \mu Y^{* *}$ & $9 / 01$ & $\circ / 9 V^{* *}$ & $\circ / \Delta \mathcal{F}^{* *}$ & $991 \mathrm{~V}^{* *}$ & $|4 \&| r D^{* *}$ & $1900 / \Gamma Q^{* *}$ & $\vee ৭ / \Delta)^{\mu * *}$ & 10 & زَنوتيب \\
\hline $1 / \mu r^{* *}$ & $T / N r^{*}$ & $\circ / \Delta \mathcal{G}^{* *}$ & $0 / 0001$ & TV^。** & TYAT & $9|0 / 9|^{* *}$ & $19 / \uparrow 9^{* *}$ & 10 & زَنوتيّ״ مكان \\
\hline 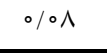 & $\Delta / r_{0}$ & $0 / 0 Y$ & $0 /{ }^{\prime}$ & 141 & raYAT & $91 / 90$ & $r / \Lambda 1$ & 90 & اشتباه دوم \\
\hline $9 / 99$ & $10 / 9 V$ & $10 / 14$ & $11 / 49$ & IKMT & $10 / 79$ & $1 \pi / 91$ & $r / T \Delta$ & - & ضغريب \\
\hline
\end{tabular}

* و ** بهتيب نشانكر معنى دار بودن در سطح آمارى بنج درصد و يك درصد است.

لذا از يتانسيل فصل رشد، استفاده كمتـرى داشـتند. در حقيقـت افزايش طول دوره روز تـا ده برگىى، منجسر بـهـ اسـتقرار ديرتـر كياهجهها و در نتيجه بهطور غيرمستقيم باعث كـاهش عملكـرد

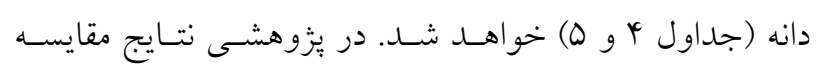

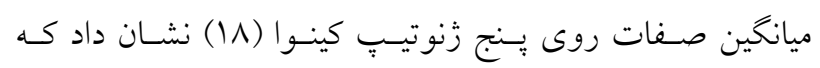

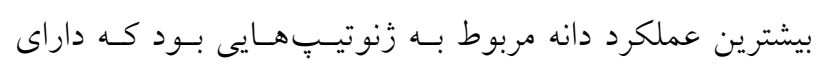

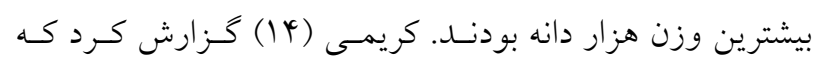
زنوتيِّهاى مطلوب كينوا با عملكرد بالا، داراى بيشترين مقادير

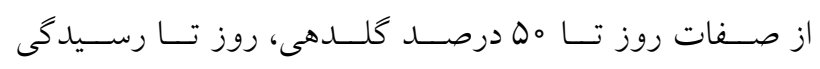
فيزيولــوزيكى، قطـر سـاقه اصـلى، تعـداد شـاخه اصـلى، طـول يانيكول، تعداد يانيكول، قطر پِانيكول و شاخص برداشت بودند.

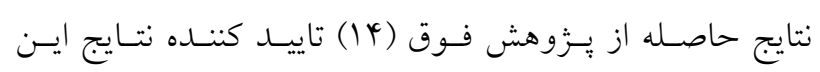
يزّوهش بوده و هر دو يزّوهش نشاندهنده نقش مهم و اساسى ئس
نتايج مقايسه ميانخين اثر متقابل بين زنوتيست در مكـان (جـدول

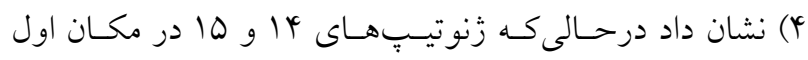
(كرج) و زنوتيـتِ شـماره 19 در مكـان دوم (كرمانشـاه) داراى بيشترين عملكرد دانه در واحد سطح بودند، زنوتيِّهـاى |ل، ه، و و ب در مكان دوم (كرمانشاه) كمترين عملكــرد را داشـتند. در

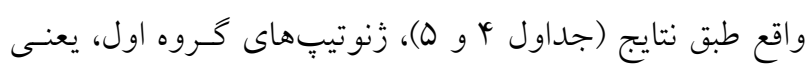

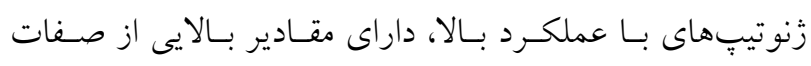
شاخص برداشت، قطر يانيكول اصلى، وزن هـزار دانـه، روز تـا تغيير رنخ يُانيكول و روز تا كلدهى بودند، بهطورى كه يكى از دلايل افزايش عملكرد در اين زنوتيبٍها، بالا بـودن مقـدار ايسن صفات در آنها است. اين درحالى است كه زنوتيـٍِهـاى گـروه دوم، يعنى زنوتيبٍهاى نامطلوب، داراى مقادير بالايى از صـفت الت روز تا ده بركى بوده و با تاخير بيشترى استقرار اوليـه داشـتند و 


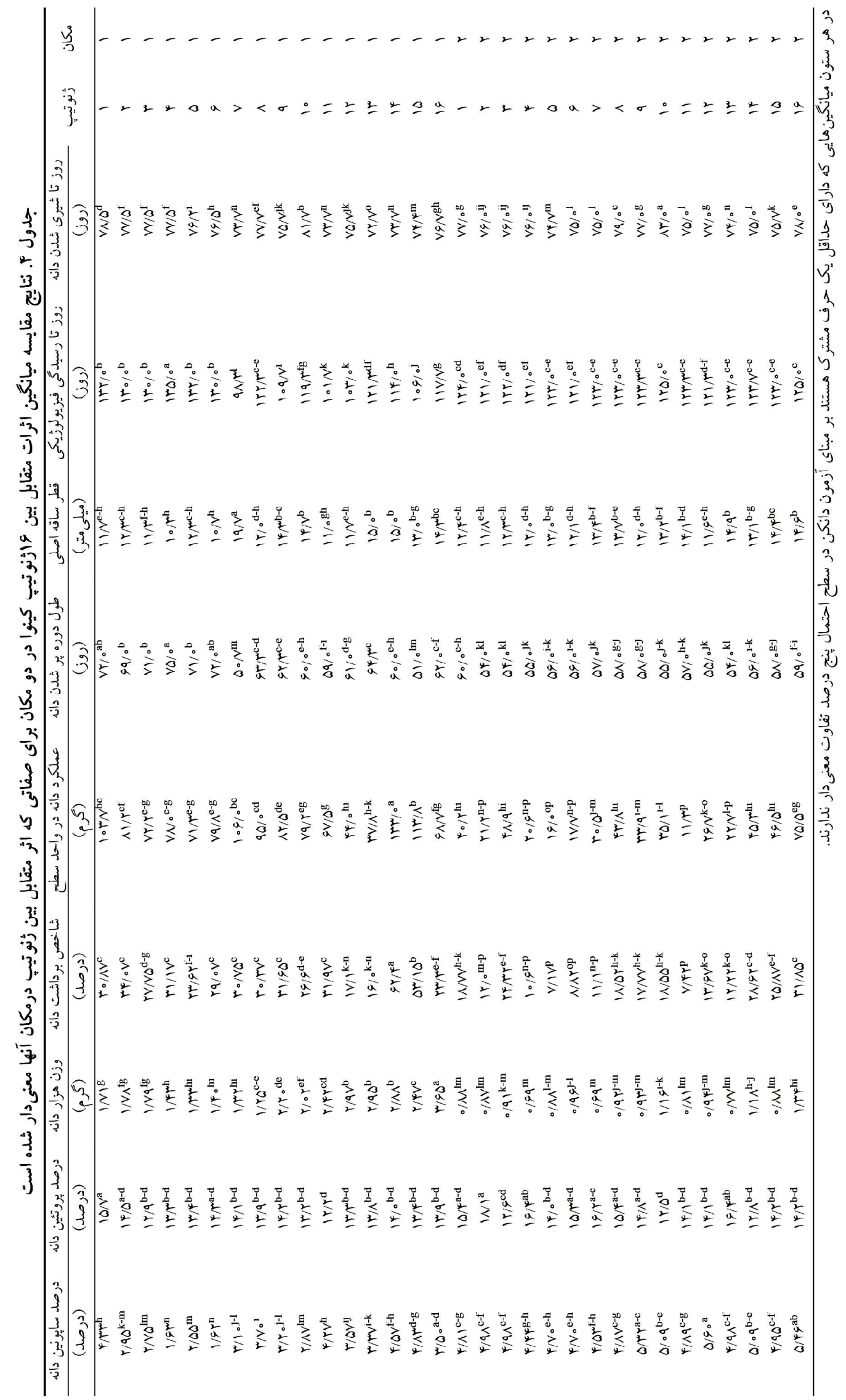




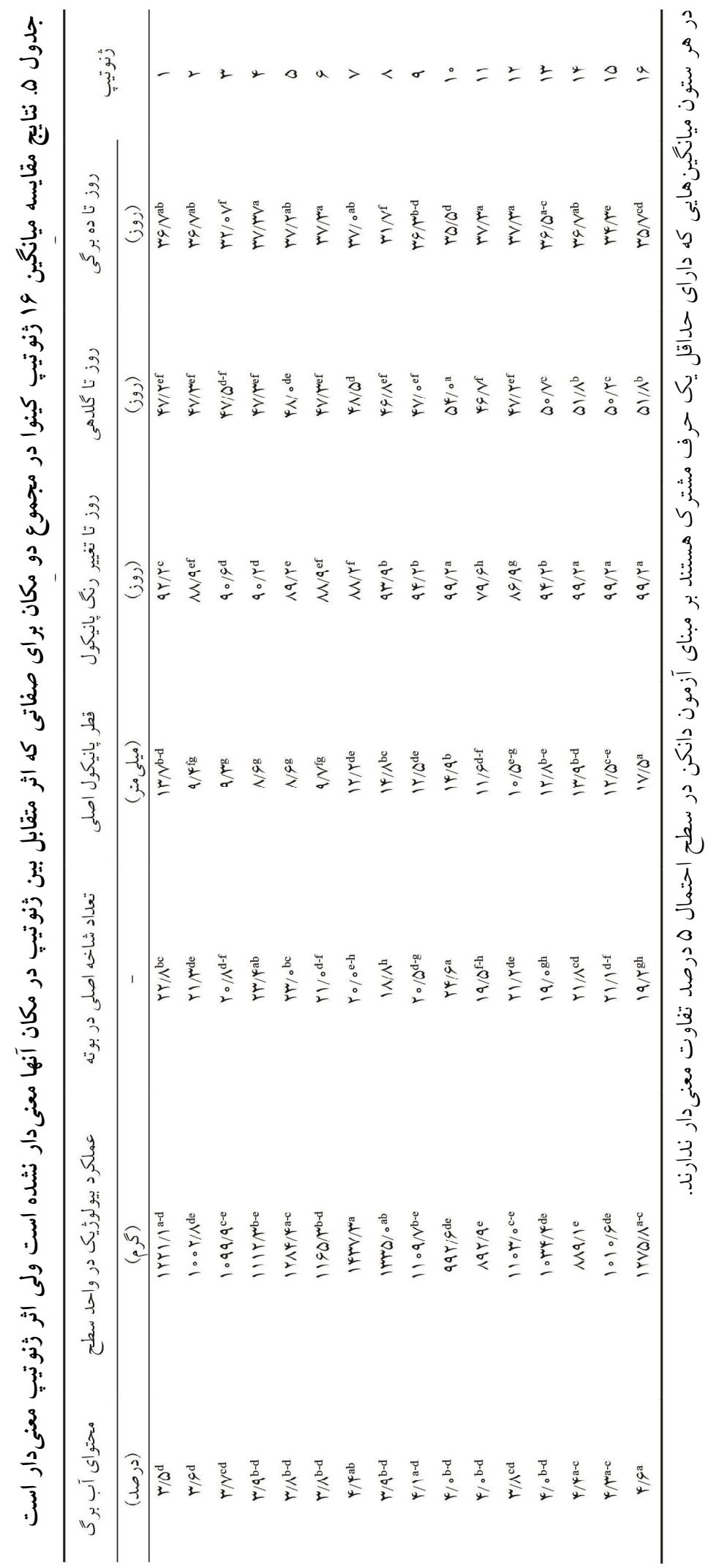


جدول و. ضرايب عاملى صفات مختلف و واريانسهاى نسبى و تجمعى عامل ها براى 19 زنوتيٍ كينوا و 10 صفت مختلف بِ از انجام دوران وريمكس و ن.

\begin{tabular}{|c|c|c|c|c|c|}
\hline ضريب عامل دوم & ضريب عامل اول & صفت & ضريب عامل دوم & ضريب عامل اول & صفت \\
\hline$-0 / 14$ & $\circ / V Q$ & عملكرد دانه در واحد سطح & $-0 / T r$ & $-0 / 04$ & روز تا ده برگى \\
\hline $0 / 1 T$ & $-0 / 04$ & عملكرد بيولوزيك در واحد سطح & $-0 / 44$ &.$/ 9 \mathrm{~V}$ & روز تا كلدهى \\
\hline$-0 / \pi r$ & $0 / 99$ & شاخص برداشت دانه & $-0 / \% V$ & $\circ / M$ & روز تا تغيير رنغ يانيكول \\
\hline$-\circ / \sqrt{ } 9$ & $\circ / \pi q$ & محتواى آب برى & $0 / 49$ &.$/ 49$ & روز تا شيرى شدن دانه \\
\hline$-0 / 4 \mathrm{~V}$ & $\circ / \Delta Y$ & 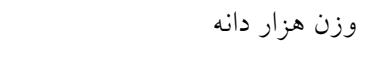 & $\circ / \wedge V$ & $\circ / 4$ & روز تا رسيدگى فيزيولوزيكى \\
\hline $0 / \Gamma 1$ & $-0 / T \Lambda$ & درصد بروتئين دانه & $-\circ / V^{4}$ & $0 / 49$ & قطر ساقه اصلى \\
\hline$-0 / 04$ & $\circ / \Delta r$ & درصد سايونين دانه & $-0 / \mu \Lambda$ & $\circ / v 9$ & قطر بانيكول اصلى \\
\hline ve & $\mu$ & درصد واريانس تجمعى عاملها & ०/AV & $0 / 09$ & طول دوره بر شدن دانه \\
\hline
\end{tabular}

البتـه ايسن بهبـود عملكـرد دانـه منـوط بـهـ ايـن اسـت كـه در اختصاص مواد فتوسنتزى توليدى به بخش هاى مختلـف كيـاه،

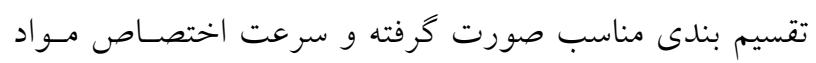

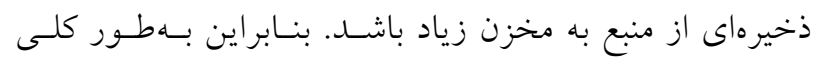

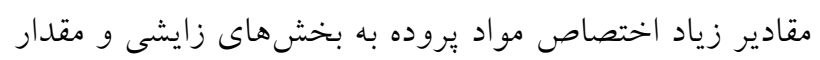

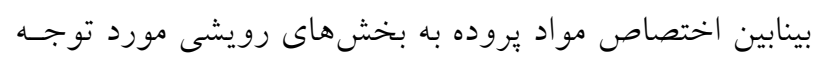

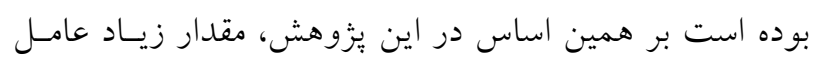
اول (با توجه به رابطه مثبت و قوى عامل اول با عملكرد دانه)

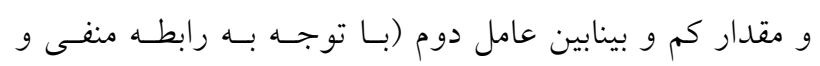

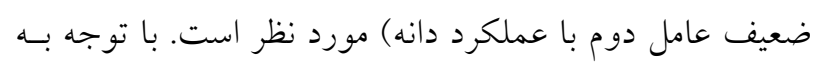

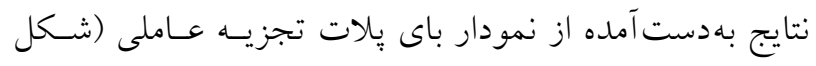

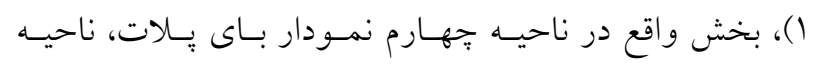

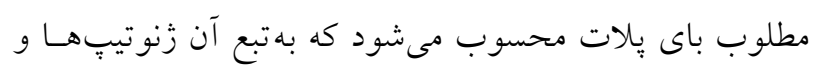

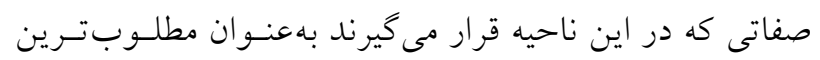

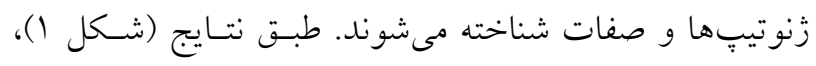

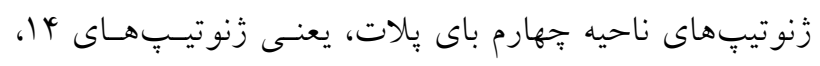

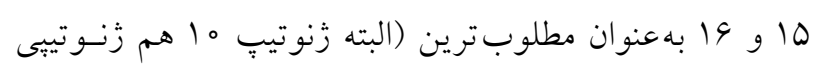

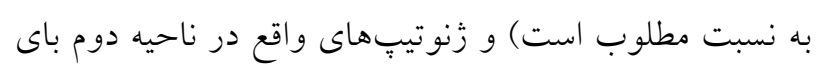

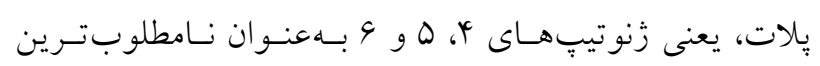

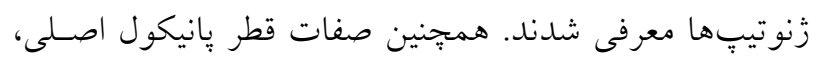

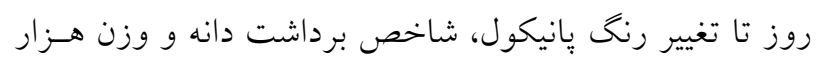

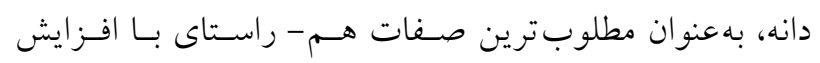

صفت پِانيكول و اجزاى بِانيكول از جمله طول يِانيكول، قطـر

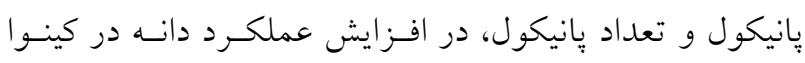

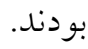

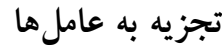

نتايج تجزيه به عامل ها پِس از انجام دوران وريمكس (جــدول 9)

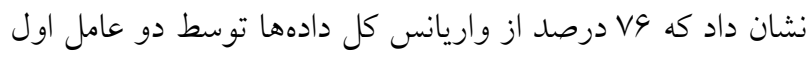
و دوم توجيه مى شود. بهطورى كه سهم عامل اول و دوم بهترتيب

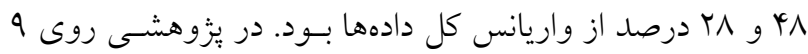

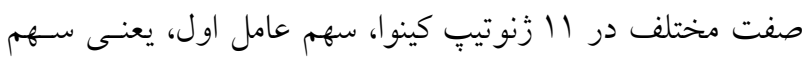

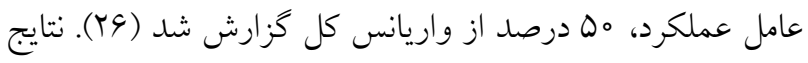

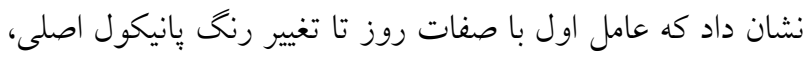

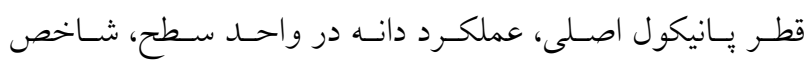

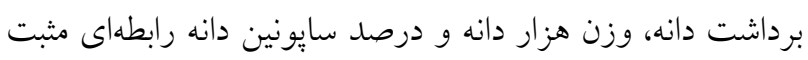

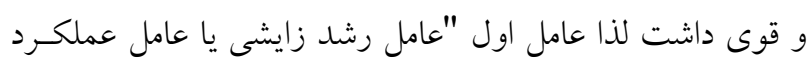

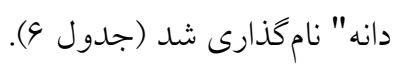

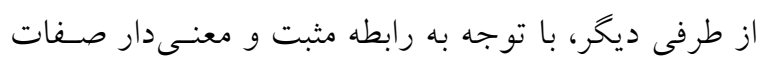

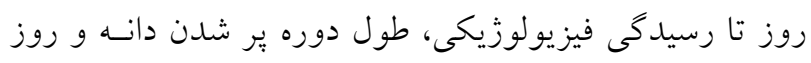

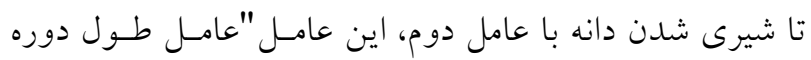

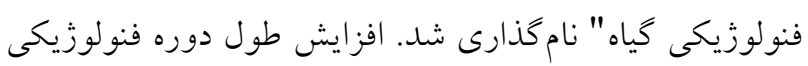
منجر به افزايش رشد رويشى مى شود كه اين افزايش منجر بــــ بهبود رشد زايشى و در نهايت بهبود عملكرد دانه خواهد شد. 


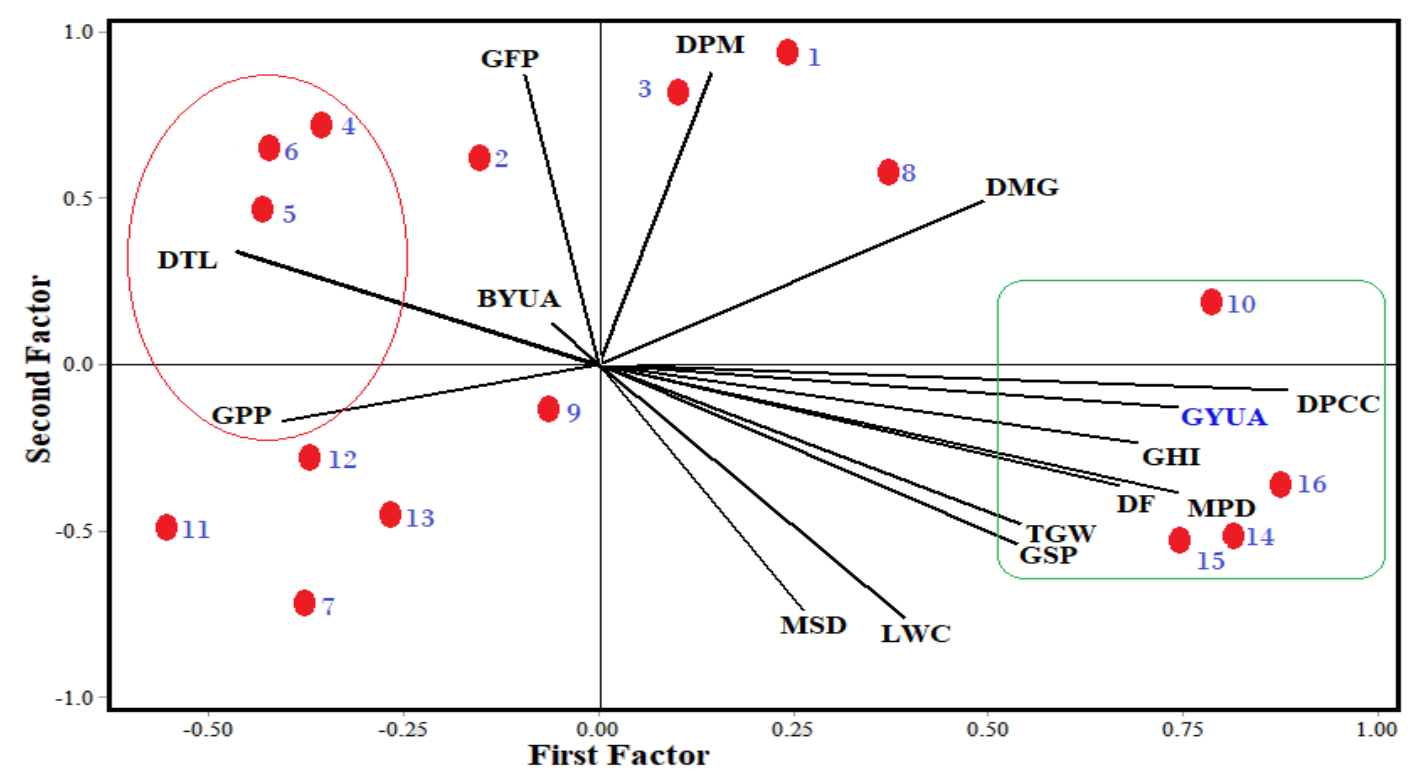

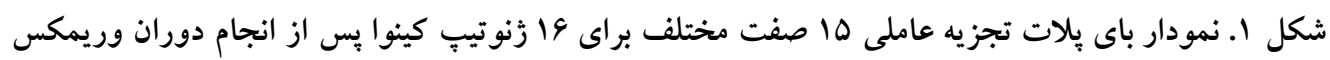

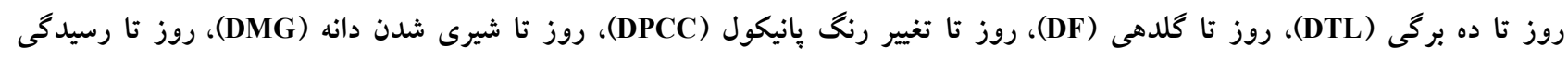

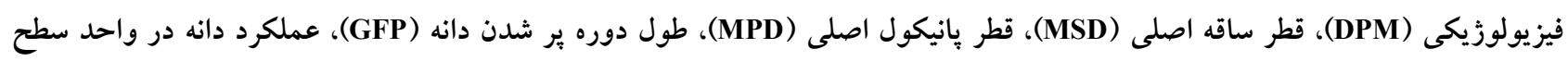

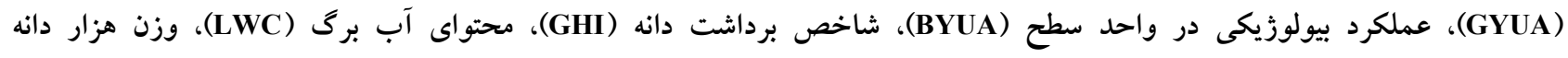

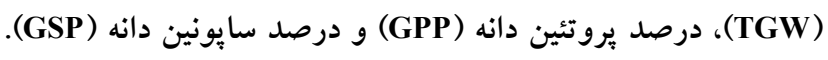

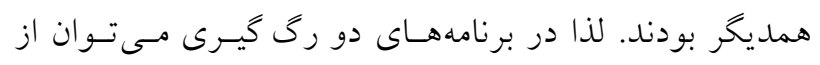

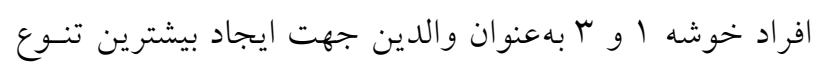

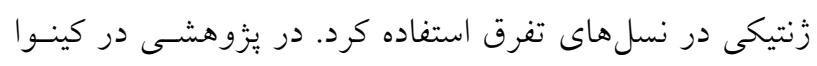

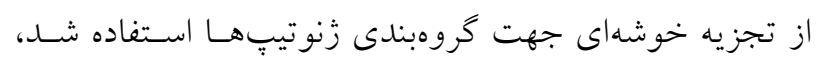

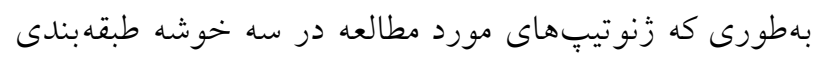

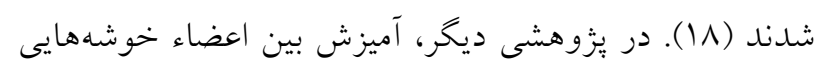

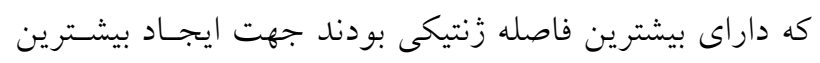

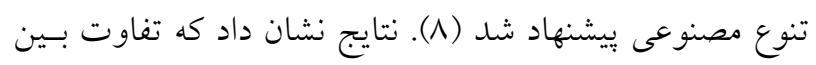

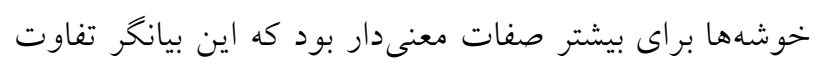

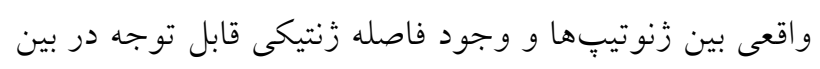

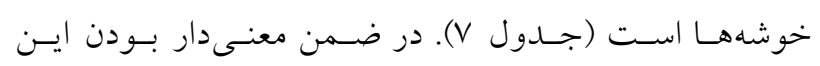

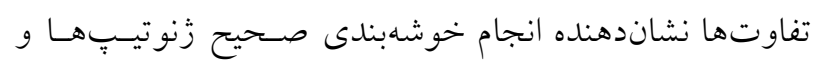

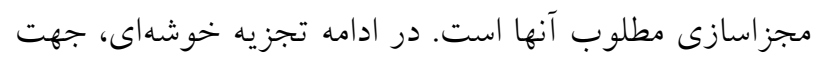

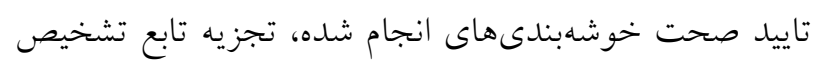

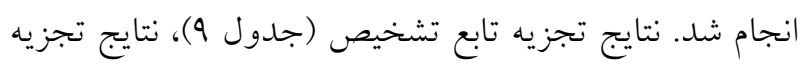

عملكرد با تأثير مثبت بر بهبود آن، شناسايى شدند. مقــدار زيـاد

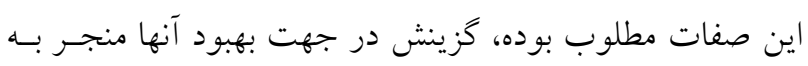

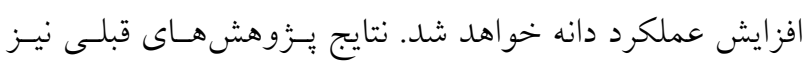
بيانكر ارتباط قوى و مثبت صفات وزن هزار دانه، قطر يـانيكول اصلى و شاخص برداشت با عملكرد دانه بودند (r و ؟ ا ).

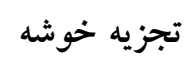

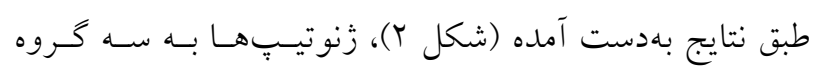

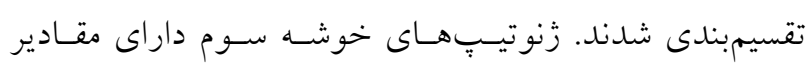

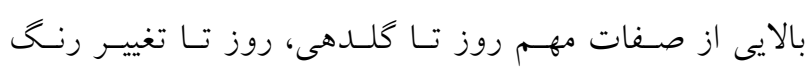

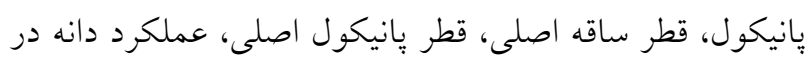

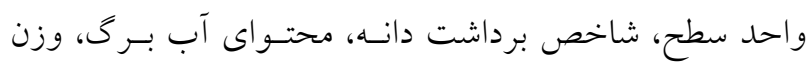

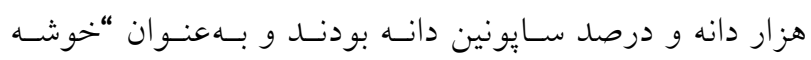

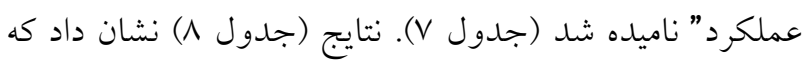

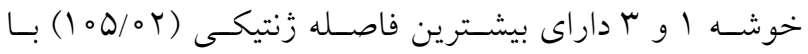




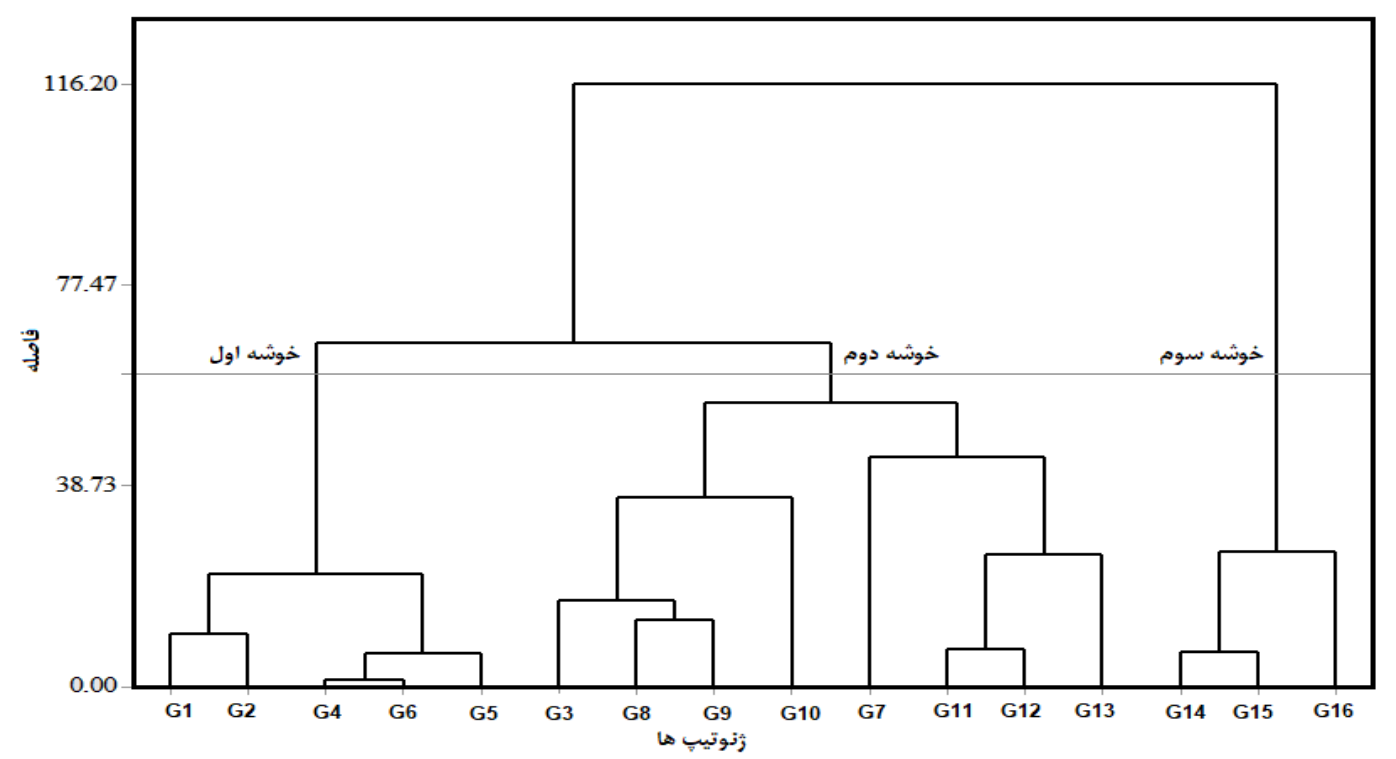

شكل r. دندروكرام 19 زنوتيٍ كينوا (G1 تا G16) بر اساس 10 صفت به روش وارد و ماتريس فاصله مربع بيرسون

جدول V نتايج مقايسه ميانخين بين سه خوشه براى صفات مطالعه شده

\begin{tabular}{|c|c|c|c|c|c|c|c|}
\hline قطر پِانيكول & قطر ساقه & فيز رسيدزي & روز تا شيرى & روز رنا تغيير & كلدهى & روز تا ده برگى & خوشه \\
\hline & (ميلى متر) & & & (روز) & & & \\
\hline $10 \% r^{b}$ & $11 / A V^{b}$ & $1 r \varepsilon / 9^{a}$ & $V G / \wedge^{4} \Lambda^{a}$ & $\wedge q / a Y^{b}$ & $\hat{k V / \mu r b}$ & $r V / \mu^{a}$ & 1 \\
\hline $\mid r / T^{\mathrm{ab}}$ & $\mid r / 4 \mu^{a}$ & $11 / 1 / 0^{b}$ & $V \& / \Delta T^{\mathrm{a}}$ & $q \circ / \Lambda \Lambda^{b}$ & $\forall \wedge / \Delta Y^{b}$ & $r \Delta / 4 \varphi^{b}$ & r \\
\hline $14 / 9 \Delta^{\mathrm{a}}$ & $\mid \psi / 0 \varphi^{\mathrm{a}}$ & $11 N / Y^{b}$ & $V Q / \Delta V^{a}$ & $৭ ৭ / r \Delta^{a}$ & $01 / T \Lambda^{\mathrm{a}}$ & $r \Delta / \Delta \varphi^{b}$ & r \\
\hline
\end{tabular}

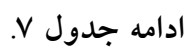

\begin{tabular}{|c|c|c|c|c|c|c|c|c|}
\hline سايونين دانه & يروتئين دانه & وزن هزار & محتواى آب برى & شاخص برداشت دانه & وبيولوزيكى در ورلكر سطح & عملكرد دانه & طول دوره ير & خوشه \\
\hline \multicolumn{2}{|c|}{ (درصد) } & (كرم) & \multicolumn{2}{|c|}{ (درصد) } & \multicolumn{2}{|c|}{ (كرم) } & (روز) & \\
\hline$r / 9 \mathrm{~V}^{b}$ & 10/०ץa & $1 / 19 b$ & $r / V Y^{b}$ & $r \circ / G Y^{b}$ & $110 \mathrm{~V} / \mathrm{IVa}$ & $\Delta r / q V^{b}$ & $94 / a^{a}$ & 1 \\
\hline $4 / 19^{a b}$ & $1 r / 99^{a b}$ & $1 / \Delta q^{b}$ & $r / 9 q^{b}$ & $r_{0} / 99^{b}$ & $\| r Q / q^{a}$ & $\Delta r / \mu I^{b}$ & $\Delta \omega / \varsigma^{a}$ & r \\
\hline $0 / \circ r^{a}$ & $1 r / v q^{b}$ & $Y / \circ V^{a}$ & $\varphi /\left.4\right|^{a}$ & $r v / \Delta \mu^{a}$ & $1 \circ \Delta \Lambda / \Delta^{b}$ & $\Lambda \circ / \varphi V^{a}$ & $\Delta V / \circ^{a}$ & r \\
\hline
\end{tabular}

مشترى هستند بر مبناى آزمون دانكن در سطح احتمال ينج درصد تفاوت معنىدار ندارند. 


\begin{tabular}{|c|c|c|}
\hline خوشه سوم & خوشه دوم & خوشه \\
\hline $100 / 0 Y$ & & خوشه اول \\
\hline$V Q / 19$ & $\%$ & خوشه دوم \\
\hline
\end{tabular}

جدول 9. نتايج تجزيه تابع تشخيص براى گروهبندى بر اساس صفات مورد مطالعه در زنوتيب هاى كينوا

\begin{tabular}{|c|c|c|c|c|c|c|c|c|}
\hline \multicolumn{8}{|c|}{ كروهبندى ييشبينى شده بر اساس تابع تشخيص } & \multirow[b]{3}{*}{ كروههاى حاصل از تجزيه خوشهاى } \\
\hline \multicolumn{2}{|c|}{ كل } & \multicolumn{2}{|c|}{$r$} & \multicolumn{2}{|c|}{$r$} & \multicolumn{2}{|c|}{1} & \\
\hline درصد & 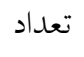 & درصد & 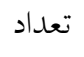 & درصد & 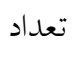 & درصد & 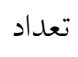 & \\
\hline 100 & 0 & 。 & $\circ$ & $\circ$ & $\circ$ & 100 & 0 & 1 \\
\hline 100 & $\wedge$ & $\circ$ & $\circ$ & 100 & $\wedge$ & $\circ$ & $\circ$ & $r$ \\
\hline 100 & $r$ & 100 & r & 。 & 。 & 。 & 。 & r \\
\hline
\end{tabular}

پانيكول اصلى ممكن است، منجر به توليد زنوتيِهاى با عملكرد بالا شود.

وجود تنوع زنتيكى در بين يك زرم يلاسم، بيـانگر نـاهمخنى زنتيكى مواد كياهى مـورد نظـر اسـت كـه ايسن نـاهمخنى امكـان

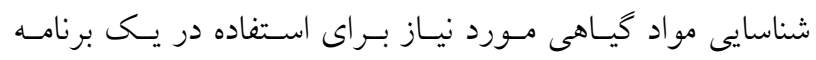

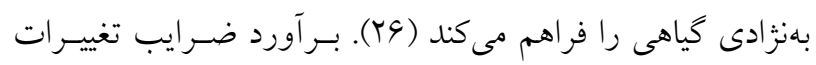
زنتيكى بالا، بيشرفت زنتيكى بالا و وراثت بذيرى بيشـتر، موجـبـ افزايش احتمال موفقيت در انتخاب زنوتيِّها بـا عملكـــد بـالاتر

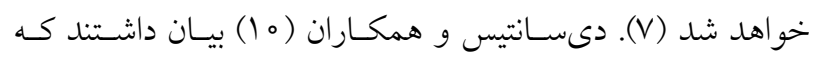
تخمين وراثت يذيرى در بيشتر صفات مطالعه شده در كينوا زيـاد

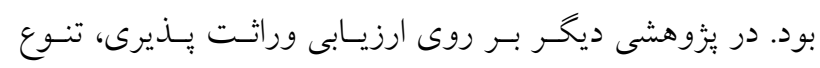
زنتيكى و بيشرفت زنتيكى بر صفات مختلـف اخرومورفولـوزيكى كينوا، وراثت يذّيرى بيشتر صفات بالا كزارش شد. بـهـــورى كـه

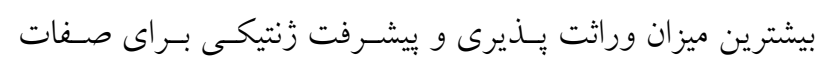

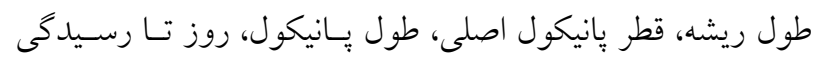

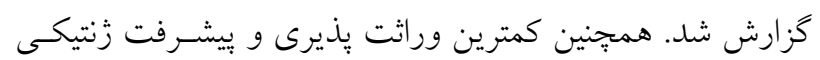
براى صفات تعداد گل آذين در بوته و وزن هزار دانه مشاهده شـد (Y). نتايج نشان داد كه هر تجقدر تفاضـل بـين ضـريب تغييـرات فنوتييى و زنوتييى كمتـر باشــ، نقـش عامـل محيطى در كنتـرل زنتيكى آن صفت كمتر و در نتيجه وراثتيذيرى آن صفت بـالاتر

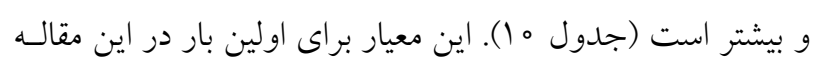

خوشهاى، يعنى گروهبندى زنوتيبها به سه خوشه، را تاييد كرد. بهورى كه صحت گروهبندىها بهطور صد در صد تاييد شد.

بر آورد يَارامترهاى زُنتيكى براى صفات مختلف طيق نتايج بهدست آمده (جدول ه (1)، زرم يلاسم مورد نظـر داراى تنوع زنتيكى بالايى براى بيشتر صـفات بـود. دو صـفت شـاخص برداشت دانه و قطر يانيكول اصلى با داشتن بيشترين ضريب تنوع زنتيكى، وراثت يذيرى بالا و بيشترين بيشرفت زنتيكى، بـهنعـوان

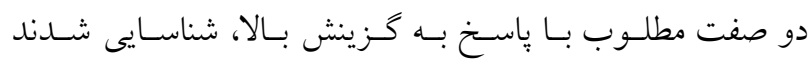
كهخزيش مثبت براى اين دو صـفت و خـزينش منفسى (كـزينش

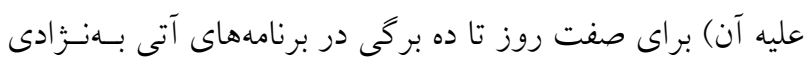
اين كياه، يِيشنهاد مىشود. در يُزوهشى روى زنوتيـٍِهـاى كينـوا، درحالى كه براى صفت عملكرد دانه وراثتيذيرى عمـومى بـالاى

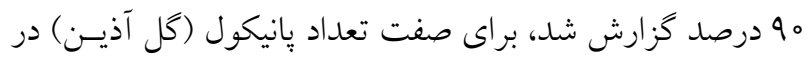
بوته، وراثت يذيرى يايينى مشاهله شد. آنها بيشـترين و كمتـرين ييشرفت زنتيكى را بهترتيب براى صفت تعـاد شـاخه در بوتسه و روز تا رسيدگى برآورد كردند (r). در يزوهشى ديخر روى كينـوا،

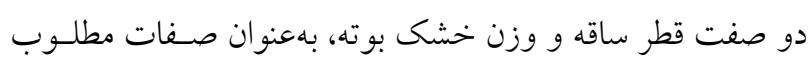

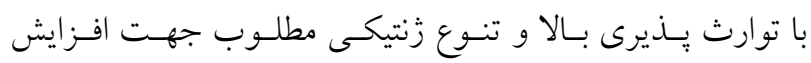

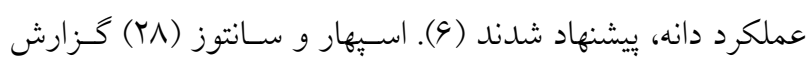
دادند كه انتخاب زنوتيِّهاى كينوا بر اساس طول پِانيكول و قطـر 
جدول • 1. بارامترهاى زُنتيكى صفات مختلف

\begin{tabular}{|c|c|c|c|c|c|}
\hline 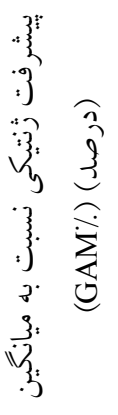 & 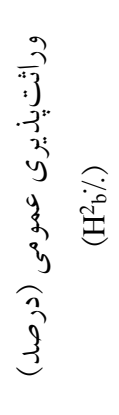 & 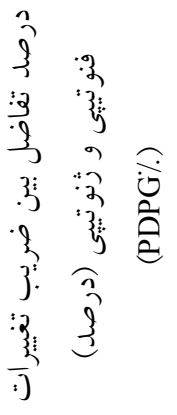 & 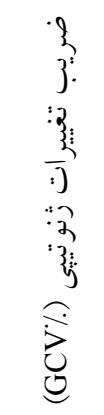 & 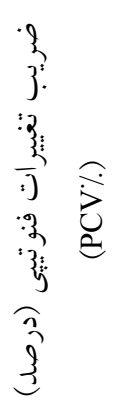 & صفات \\
\hline V/GY & $99 / 9 \circ$ & $1 / 09$ & $\varphi / \varphi_{0}$ & $\varphi / \& V$ & روز تا ده بركى \\
\hline $\mathrm{V} / \mathrm{IT}^{\mathrm{C}}$ & $4 \& / \pi$ & $1 / 19$ & $\varphi / l r$ & $\varphi / r 1$ & روز تا كلدهى \\
\hline V/VG & $9 V / 14$ & $1 / 44$ & $\varphi / \varphi v$ & $\varphi / \Delta r$ & روز تا تغيير رنخ يانيكول \\
\hline r/Qr & $90 / 91$ & $r / 0 r$ & $r / 9 r$ & $r / 9 \Lambda$ & روز تا شيرى شدن دانه \\
\hline $1 / 4 r$ & $r M / T \varphi$ & $01 / \mathrm{WV}$ & $1 / 91$ & $r / \uparrow \wedge$ & روز تا رسيدگى فيزيولوزيك \\
\hline $10 / T^{4}$ & $91 / \pi$ & rI/VO & $V / \mu^{4}$ & $9 / 0 \circ$ & قطر ساقه اصلى \\
\hline rg/QT & $90 / 01$ & r/Qr & $r / / r q$ & $r M / N$ & قطر بانيكول اصلى \\
\hline $1 / \Lambda r$ & $r r / \Delta r$ & $01 / 49$ & $r / l \varphi$ & $Y / 4 T$ & طول دوره ير شدن دانه \\
\hline$r V / q 1$ & $9 N / 10$ & $\mid V / \varphi \Lambda$ & $19 / T 1$ & $r$ rr/YA & عملكرد دانه در واحد سطح \\
\hline IV/ar & $\Delta F / \Delta Q$ & $r 9 / 11$ & $\mid r / N \Lambda$ & $1 / 190$ & عملكرد بيولوزيكى در واحد سطح \\
\hline $41 / 11$ & $V N / \uparrow \Lambda$ & $\mid 1 / 41$ & TANV & $r q / N V$ & شاخص برداشت دانه \\
\hline $11 / \circ r$ & $99 / 94$ & $\mid N / T V$ & $V / 9 V$ & $9 / 4 \circ$ & محتواى آب برى \\
\hline$r Y / 4 q$ & $9 V / r)$ & $M / 0 r$ & $19 / 9 \mathrm{~V}$ & $r \circ / V_{0}$ & وزن هزار دانه \\
\hline $0 / \Delta 1$ & $r \Delta / v a$ & $r \circ / r 1$ & $Q / Y Y$ & $\Lambda / V q$ & درصد بِروتئين دانه \\
\hline $1 \% / r \Delta$ & $q V / 4 \circ$ & $1 V / 90$ & $9 / \wedge 9$ & $|r / 0|$ & درصد سايونين دانه \\
\hline
\end{tabular}

جدول 11. همبستحى ساده بين سه بارامتر زنتيكى درصد تفاضل بين ضريب تغييرات فنوتيى و ضريب تغييرات زنوتيبى، وراثت يذيرى عمومى

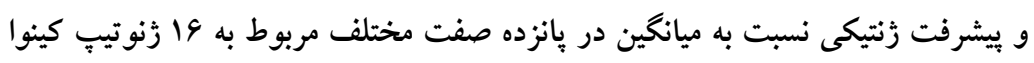

\begin{tabular}{|c|c|c|}
\hline بيشرفت زنتيكى نسبت به ميانخين & وراثت بذيرى عمومى & 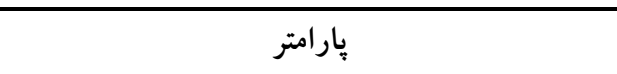 \\
\hline$-0 / \mu_{4}$ & $-0 / 99 \uparrow^{* * *}$ & درصد تفاضل بين ضريب تغييرات فنوتييى و زنوتييى \\
\hline$\circ \pi r$ & 1 & وراثت بذ يذيرى عمومى \\
\hline
\end{tabular}

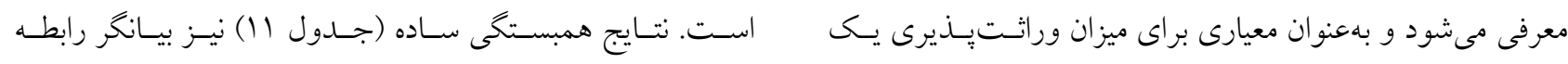

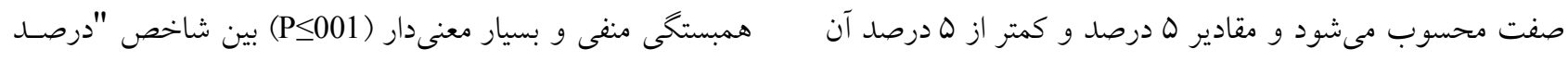

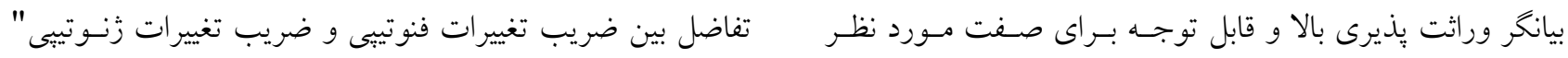




$$
\begin{aligned}
& \text { يانيكول اصلى و شاخص برداشت دانه) يِشنهاد مىشود. عـلاوه } \\
& \text { و "مقدار وراثتيذيرى عمـومى "صـفات مـورد مطالعسه بـود. در } \\
& \text { بر اين، انجام همزمان گزينش منفى براى صفت روز تا ده برگى } \\
& \text { واقع با كـاهش مفـدار ايـن شـاخص، سـهم انحــراف محيطى از } \\
& \text { كه منجر به استقرار سريعتر كياهجههــا در مراحـل اوليـه رشــ، }
\end{aligned}
$$

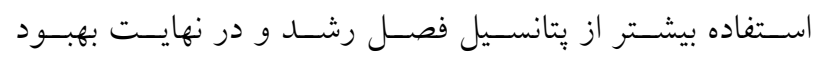

$$
\begin{aligned}
& \text { غيرمستقيم عملكرد دانه خواهد شد، تحت شرايط اين آزمـايش } \\
& \text { قابل توصيه است، هر جنــد كـه تكــرار آزمـايش در سـالهـا و } \\
& \text { مكانهاى بيشتر باعث اطمينان بيشتر در قضاوت ما خواهد شـد. } \\
& \text { در پِايان استفاده از يارامتر جديد "درصــ تفاضـل بـين ضـريب } \\
& \text { تغييرات فنوتيى و ضريب تغييرات زنوتييى" بـر اسـاس رابطـه }
\end{aligned}
$$

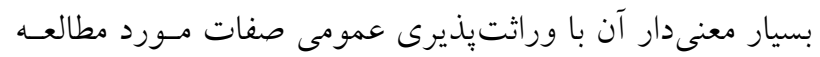

$$
\begin{aligned}
& \text { (r= o994***)، مطلوب بوده، توصيه مىشود. } \\
& \text { واريانس كل كاسته مىشود و سـهم واريـانس زنتيكسى در كنتـرل } \\
& \text { صفت افزايش خواهد يافت. علىرغم وجود رابطه منفى بسين ايسن }
\end{aligned}
$$

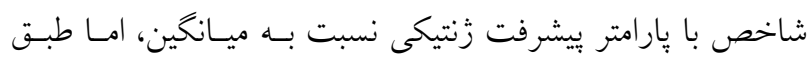

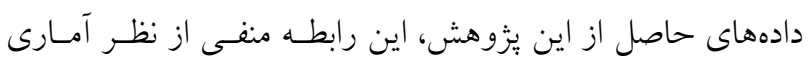

$$
\begin{aligned}
& \text { معنى دار نبود (جدول (1). } \\
& \text { تتيجه كيرى } \\
& \text { طبق نتايج اين يزوهش، تنوع زنتيكى و بيشرفت زنتيكى مطلوبى } \\
& \text { در بين زنوتيِهاى مطالعه شده در اين گياه نوظهـور در ايسران، } \\
& \text { براى بيشتر صفات مشاهده شد كه نشاندهنده مفيد بودن انجـام } \\
& \text { سياسخزارى } \\
& \text { نخارند گان مقاله به خاطر همكارىها و كمكهاى ارزنده رياست } \\
& \text { محتـرم و ديخــ همكسـاران كرامسى يــارى دهنـده مـا در مركـز } \\
& \text { تحقيقات، ترويج و آمـوزش كشـاورزى و منــابع طبيعسى اسـتان } \\
& \text { كرمانشاه و موسسه تحقيقات اصلاح و تهيه نهـال و بــذر كـرج، } \\
& \text { كمال تشكر و قدردانى را دارند. } \\
& \text { كزينش اوليه در زرم پِاسم حاضر است. زنوتيـيٌهــاى شـماره } \\
& \text { ץ ا، ها و } 19 \text { در مجموع دو مكان ارزيابى شـده، داراى صـفات } \\
& \text { مطلوب و عملكرد بالايى بودند كه مىتوان از يتانسـيل زنتيكى }
\end{aligned}
$$

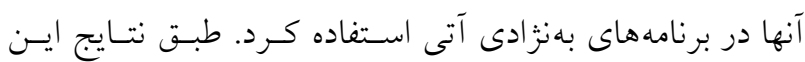

$$
\begin{aligned}
& \text { يزّوهش انجام گزينش مثبت براى صفات قطـر بـانيكول اصـلى، }
\end{aligned}
$$

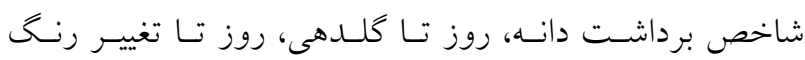

$$
\begin{aligned}
& \text { يانيكول و وزن هزار دانه (بهويـزه دو صـفت بسـيار مهـم قطـر }
\end{aligned}
$$

\section{منابع مورد استفاده}

1. Abugoch, L., E. Castro, C. Tapia, M. C. Anon, P. Gajardo and A. Villarroel. 2009. Stability of quinoa flour proteins (Chenopodium Quinoa Willd.) during storage. International Journal of Food Science and Technology 44(10): 20132020.

2. Afiah, S. A., W. A. Hassan and A. Al Kady. 2018. Assessment of six quinoa (Chenopodium Quinoa Willd.) genotypes for seed yield and its attributes under Toshka conditions. Zagazig Journal of Agricultural Research 45(6): 2281-2294.

3. Al-Naggar, A., R. Abd El-Salam, A. Badran and M. M. El-Moghazi. 2017. Genotype and drought effects on morphological, physiological and yield traits of quinoa (Chenopodium Quinoa Willd.). Asian Journal of Advances in Agricultural Research 3(1): 1-15.

4. Al-Tabbal, J. A. and A. H. Al-Fraihat. 2012. Genetic variation, heritability, phenotypic and genotypic correlation studies for yield and yield components in promising barley genotypes. Journal of Agricultural Science 4(3): 193210.

5. Bazile, D., C. Pulvento, A. Verniau, M. S. Al-Nusairi, D. Ba, J. Breidyand and M. Otambekova. 2016. Worldwide evaluations of quinoa: preliminary results from post international year of quinoa FAO projects in nine countries. Frontiers in Plant Science 7: 1-18.

6. Bhargava, A., S. Shukla, R. S. Katiyar and D. Ohri. 2003. Selection parameters for genetic improvement in Chenopodium grain on sodic soil. Journal of Applied Horticalture 5: 45-48.

7. Cargnelutti, F. A., L. Storck and N. D. Ribeiro. 2009. Medidas da precisão experimental em ensaios com genótipos 
de feijão e de soja. Pesquisa Agropecuária Brasileira 44(10): 1225-1231.

8. Chauhan, G. S., N. Eskin and R. Tkachuk. 1999. Effect of saponin extraction on the nutritional quality of quinoa (Chenopodium quinoa Willd.). Journal of Food Science and Technolgy 36: 123-126.

9. De Santis, G., T. D'ambrosio, M. Rinaldi and A. Rascio. 2016. Heritabilities of morphological and quality traits and interrelationships with yield in quinoa (Chenopodium Quinoa Willd.) genotypes in the Mediterranean environment. Journal of Cereal Science 70: 177-185.

10. De Santis, G., P. De Vita, E. Carlino, S. Colecchi and L. D'Angelo. 2009. Valutazione di caratteri morfologici in genotipi di quinoa (Chenopodium quinoa Willd.) in ambiente Mediterraneo. In: Proc. 4th Meeting Piante Mediterranee, Oct. 2009, Nova Siri Marina (MT) Italia. 270-275.

11. Elsohaimy, S., T. Refaay and M. Zaytoun. 2015. Physicochemical and functional properties of quinoa protein isolate. Annals of Agricultural Sciences 60(2): 297-305.

12. Falconer, D. S. 1989. Introduction to Quantitative Genetics. Longman. New York.

13. Jacobsen, S. E. 2003. The worldwide potential for quinoa (Chenopodium quinoa Willd.). Food Reviews International 19(2): 167-177.

14. Karimi, S. H. 2018. Assessing adaptation and diversity of quinoa ecotypes by morphological ann SSR markers in different moisture conditions. MSc Thesis. Bu-Ali Sina University. Hamadan, Iran.

15. Kaul, H. P., M. Kruse and W. Aufhammer. 2005. Yield and nitrogen utilization efficiency of the pseudocereals amaranth, quinoa, and buckwheat under differing nitrogen fertilization. European Journal of Agronomy 22(1): 95100.

16. Koziol, M. J. 1991. Afrosimetric estimation of threshold saponin concentration for bitterness in quinoa (Chenopodium quinoa Willd). Journal of the Science of Food and Agriculture 54(2): 211-219.

17. Kuster, I. and N. Vila. 2017. Health/nutrition food claims and low-fat food purchase: projected personality influence in young consumers. Journal of Functional Foods 38: 66-76.

18. Mohyuddin, S., A. Riaz, A. Qamar, S. Ali, C. Hu, L. Wu and X. Ju. 2019. Quinoa is beneficial to the comprehensive nutritional value of potential health. Pakistan Journal of Science 70(2): 69-74.

19. Montano Reyes, E. A., D. P. Avila Torres and J. O. Guevara Pulido. 2006. Componente nutricional de diferentes variedades de quinua de laregión andina. Avances Investigacion en Ingenieria 5: 86-97.

20. Movlaei, A. and M. Bagheri. 2020. Yield comparison of quinoa genotype in shahre-kord. In: Proceeding of $16^{\text {th }}$ National Congress of Agricultural Sciences and Plant Breeding of Iran. Shahre-Kord, Iran. 25-27 January 2020. pp. 4. (In Farsi).

21. Navruz-Varli, S. and N. Sanlier. 2016. Nutritional and health benefits of quinoa (Chenopodium Quinoa Willd.). Journal of Cereal Science 69: 371-376.

22. Pycia, K., K. Gesinski, G. Jaworska and B. Barczak. 2019. Comparative analysis of selected physicochemical properties of quinoa (Chenopodium Quinoa Willd.), maize, wheat and potato starch. Journal of Central European Agriculture 20(2): 626-635.

23. Rahimi, E. and M. Bagheri. 2020. Chemical, antioxidant, total phenolic and flavonoid components and antimicrobial effects of different species of quinoa seeds. Egyptian Journal of Veterinary Sciences 51(1): 43-54.

24. Risi, J. C. and N. W. Galwey. 1989. The pattern of genetic diversity in the Andean grain crop quinoa (Chenopodium quinoa Willd). I. Associations between characteristics. Euphytica 41: 147-162.

25. Rodríguez. L. A. and M. T. Isla. 2013. Comparative analysis of genetic and morphologic diversity among quinoa accessions (Chenopodium quinoa Willd.) of the south of Chile and highland accessions. African Journal of Plant Breeding 1(7): 130-135.

26. Ruiz, K., S. Biondi, R. Oses, I. Acuña, F. Antognoni, E. Martínez, A. Coulibaly, A. Canahua, M. Pinto, A. Zurita, D. Bazile, S. Jacobsen and M. Molina. 2014. Quinoa biodiversity and sustainability for food security under climate change. A review. Agronomy for Sustainable Development 34(2): 349-359.

27. Sifati, S. A., S. S. Ramazanpoor, H. Soltanlu, M. Salehi and N. Sepahvand. 2015. Study on some morphophenological traits related to yield and early maturity in quinoa cultivars (Chenopodium quinoa Wild.). Journal of Crop Production 8(2): 153-169. (In Farsi).

28. Spehar, C. R. and R. L. D. Santos. 2005. Agronomic performance of quinoa selected in the Brazilian Savannah. Pesquisa Agropecuária Brasileira 40(6): 609-612.

29. Vasconcelos, F. S., E. S. Vasconcelo, M. G. Balan and L. Silvério. 2012. Development and productivity of quinoa sown on different dates the during off-season. Ciência Agronômica 43(3):510-515.

30. Vega-Galvez, A., M. Miranda, J. Vergara, E. Uribe, L. Puente and E. A. Martínez. 2010. Nutrition facts and functional potential of quinoa (Chenopodium quinoa willd.), an ancient Andean grain: A review. Journal of Science Food and Agriculture 90: 2541-2547. 


\title{
Evaluation of Diversity and Application of Agronomic, Morphological, and Physiological Traits to Improve Quinoa (Chenopodium quinoa Willd.) Grain Yield
}

\author{
S. S. Moosavi ${ }^{1 *}$, R. Moradi Rizvandi ${ }^{2}$, M. R. Abdollahi ${ }^{3}$ and M. Bagheri ${ }^{4}$
}

(Received: April 24-2021; Accepted: August 07-2021)

\begin{abstract}
The purpose of this study was to evaluate the diversity and predict the response to selection in different traits of 16 quinoa genotypes, which was done in a randomized complete block design in Karaj and Kermanshah. The genotypes had a statistically significant difference $(\mathrm{p} \leq 0.01)$ for the majority of the traits, and they were distributed in four biplot regions. Genotypes 14, 15, and 16 had the highest, and genotypes 5 and 6 had the lowest grain yield and grain harvest index. While the main panicle diameter, grain harvest index, day to physiological maturity, day to main panicle color change, 1000-grain weight, and day to flowering had the highest positive alignment with yield component, day to ten leaf trait had a strong but negative connection with it. The highest genetic distance was observed between the first and third clusters, which can be achieved by crossing the selected genotypes of these two clusters, to create the greatest genetic diversity in the dividing generations. Grain harvest index and diameter of the main panicle with the highest coefficient of genetic diversity, high heritability, and the highest genetic progression were identified as two desirable traits with a high selection response. Positive selection for these two traits and negative selection for day to ten leaf traits are suggested in future breeding programs of this plant. In general, due to the limitation of direct selection to improve grain yield, also according to the significant correlation $\left(r=0.994^{* * *}\right)$ between the new parameter of "percentage difference between phenotypic variation coefficient and genotypic variation coefficient" with broad-sense heritability, the use of this new genetic parameter to select desirable agro morphophysiological traits is recommended.
\end{abstract}

Keywords: Qualitative traits, Morphophysiological traits, Response to selection, Factor analysis, Cluster analysis

1, 2 and 3. Associate Professor M.Sc. Student and Associate Professor, Respectively, Department of Agronomy and Plant Breeding, Faculty of Agriculture, Bu-Ali Sina University, Hamedan, Iran

4. Assistant Professor of Seed and Plant Improvement Institute, Agricultural Research, Education and Extension Organization (AREEO), Karaj, Iran

*: Corresponding Author, Email: s.moosavi@basu.ac.ir 